University of Louisville

ThinkIR: The University of Louisville's Institutional Repository

Electronic Theses and Dissertations

$12-2013$

\title{
Territoriality and landscape of aggression.
}

Piyumika Sureshni Suriyampola

University of Louisville

Follow this and additional works at: https://ir.library.louisville.edu/etd

\section{Recommended Citation}

Suriyampola, Piyumika Sureshni, "Territoriality and landscape of aggression." (2013). Electronic Theses and Dissertations. Paper 1410.

https://doi.org/10.18297/etd/1410

This Doctoral Dissertation is brought to you for free and open access by ThinkIR: The University of Louisville's Institutional Repository. It has been accepted for inclusion in Electronic Theses and Dissertations by an authorized administrator of ThinkIR: The University of Louisville's Institutional Repository. This title appears here courtesy of the author, who has retained all other copyrights. For more information, please contact thinkir@louisville.edu. 


\title{
TERRITORIALITY AND LANDSCAPE OF AGGRESSION
}

\author{
By
}

Piyumika Sureshni Suriyampola

B.Sc. University of Peradeniya, 2006

M.S. University of Louisville, 2013

\begin{abstract}
A Dissertation
Submitted to the Faculty of the

College of Arts and Sciences of the University of Louisville in Partial Fulfillment of the Requirements

for the Degree of
\end{abstract}

Doctor of Philosophy

Department of Biology

University of Louisville

Louisville, Kentucky

December 2013 
Copyright 2013 by Piyumika Sureshni Suriyampola

All rights reserved 



\title{
TERRITORIALITY AND LANDSCAPE OF AGGRESSION
}

\author{
By
}

Piyumika Sureshni Suriyampola

B.Sc. University of Peradeniya, 2006

M.S. University of Louisville, 2013

A dissertation approved on

October 25, 2013

by the following Dissertation Committee:

Dissertation Director- Dr. Perri Eason

Dr. Paul Ewald

Dr. William Pearson

Dr. James Alexander

Dr. Omar Attum 


\section{DEDICATION}

I lovingly dedicate this dissertation to my parents

For encouraging me to follow my dreams,

And to my son Tharul

Who has yet to explore the wonders of the natural world. 


\section{ACKNOWLEDGEMENTS}

I thank everyone who have supported me and helped me along the way to compete this dissertation. I am most grateful to my advisor, Dr. Perri Eason for all her support and patience. She has been a remarkable mentor, always willing to make room in her schedule to work with me, read my endless drafts and to answer questions. Thank you for accepting me into your lab, taking me to awesome places, helping me in the field, and being my dive buddy. Dr. Eason has taught me a great deal about science as well as life. I am also thankful to my committee members Dr. Paul Ewald, Dr. William Pearson, Dr. James Alexander and Dr. Omar Attum for agreeing to bear with me during my graduate career and for providing valuable advice and constructive criticism throughout.

I greatly appreciate all the good times and the honest comments provided by my previous and current lab mates. They listened to my talks and suffered reading my drafts. I am glad that I got to meet and spend time with Dr. Chad Hanna and Dr. Catie ByersHanna, two of my favorite people and the veterans of the Eason lab. Carl Cloyed is a wonderful friend and taught me how to juggle and play racquet ball. I am sure I am going to miss your "turkey songs". Thank you, Sarah Ramaker, for feeding and taking care of my fish when I was away. I would also like to thank all the graduate students for the emotional support and making me feel at home here. A big shout out to Dr. Allison Smith. I am glad we met! I also thank all the biology staff for pointing me in the right direction those many times when I had no idea what I was doing. 
I am thankful to Dr. Ryan Early for mentioning Lake Xiloá to Dr. Eason, when I was so frustrated with lab experiments. I would be amiss if I did not mention the cichlids; you are such amazing creatures, thanks for re-igniting my passion for field studies. Dr. Kenneth McKaye and Dr. Eric van den Bergh provided important logistical support in Nicaragua. Thank you Louis and Diego for helping me to carry the heavy dive gear.

Funding for my research was provided by American cichlid association, Ideawild, International center of University of Louisville, Biology Graduate Student Association, Graduate Student Council and College of Art and Sciences, University of Louisville.

The research presented here was described in Animal Research protocols No.08066 and No.12117 approved on August 3, 2008 and February 6, 2013, respectively, by the Institutional Animal Care and Use committee of the University of Louisville.

Lastly, I could not have achieved what I have thus far without my remarkable family. I thank my parents for teaching me the value of education and hard work. You taught me to follow my heart in pursing my dreams without thinking of the money that I would earn one day. I am also thankful to my husband, Buddika Abeyweera for sticking by me and putting up with my endless fascination with the wonders of the natural world. Thank you, Tharul, for loving me unconditionally even though I had to leave you briefly to continue my research in Nicaragua. I hope you will grow into a man who appreciates and respects Mother Nature. 


\title{
ABSTRACT \\ TERRITORIALITY AND LANDSCAPE OF AGGRESSION
}

\author{
Piyumika S. Suriyampola
}

October 25, 2013

Behavioral adjustments in response to the presence of landmarks can exert strong effects on population dynamics of territorial species as well as the evolution of behavior and social systems. Hence, an understanding of the role of landmarks in animal contests provides a link between behavioral decision-making and population dynamics, which has been viewed as a major goal in ecology. This dissertation investigates the effects of landmarks on territory defense, focusing on how landmarks affect differences in sex roles, the landscape of aggression and fundamental territory properties. To investigate these ideas, I used three different cichlid fish species as model systems. My results clearly demonstrate that landmarks have strong effects on territoriality of cichlid fish, and thus are likely to have been significant influences on the population dynamics and the evolution of the behavior.

The laboratory experiments revealed that the resource-free space between territories can function as a visual landmark to reduce aggression between territorial neighbors. I found that male and female Neolamprologus multifasciatus, an African shellbrooding cichlid fish, respond differently to changes in defensive costs that arose as a 
result of the presence/absence of a buffer zone. Males were more sensitive to the effect of increased defensive costs, compared to females as males increased both the time spent in defense and the use of highly aggressive acts. This increased responsiveness of males could be partly due to males having stronger tendency to intrude when a buffer zone is absent. This study also suggests that, at least in some species, females' contribution to territory defense may vary relatively little regardless of overall costs.

Visual landmarks also influenced the landscape of aggression in Hypsophrys nicaraguensis, a Central American cichlid fish. Findings of this field study revealed that in the absence of landmarks fish left larger areas between each other, and these spaces may act as buffer zones. In addition, this work found that landmarks are useful in both precisely defining territory borders and allowing fish to interact at landmarks when such landmarks are available. These factors may have contributed to lower the overall defensive costs in several ways, by decreasing accidental intrusions, reducing risk of escalation, easily identifying when an intrusion is occurring, and spending less time in boundary patrolling.

Landmarks also affected the fundamental territory properties such as territory size, shape and the location of boundaries in Amatitlania siquia territories. In this field study, I observed that territories were significantly smaller when landmarks were present. The reduced size was mainly driven by relocating the boundary closer to the landmark, with pairs giving up an area lacking a clearly defined boundary. This behavior suggests that it is beneficial to defend a smaller territory with well-defined boundaries compared to a larger territory with undefined territory borders. The willingness of fish to move the boundary closer to the nest also suggests that landmarked boundaries provide benefits 
substantial enough to overcome the cost of high predation on fry when the boundary is closer to the nest. In addition, with the presence of a linear landmark, territories were elongated. However, the presence of a point landmark did not alter territories' optimal round shape.

Findings of my dissertation will provide a means by which researchers will be able to manipulate territories and address fundamental questions about territory structure, territory function as well as the evolution of territoriality and its role in population dynamics. In addition to contributing to the knowledge base of territoriality, these results have important implications for wildlife managers and captive breeders as it suggests that providing landmarks maximizes space use and reduces aggression in territorial species. 


\section{TABLE OF CONTENTS}

ACKNOWLEDGEMENTS ............................................................................. IV

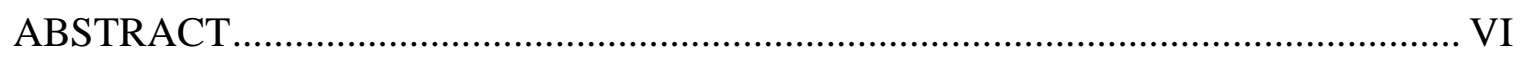

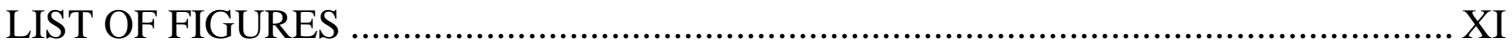

\section{CHAPTER}

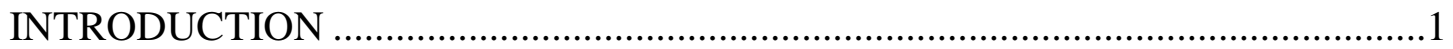

I SEX DIFFERENCES IN TERRITORIAL DEFENSE .........................................8

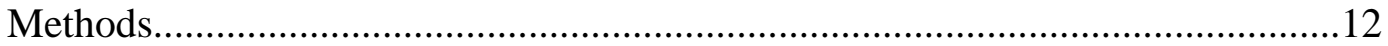

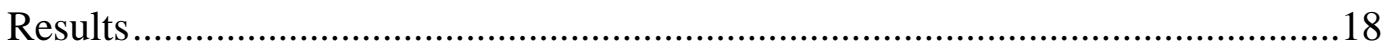

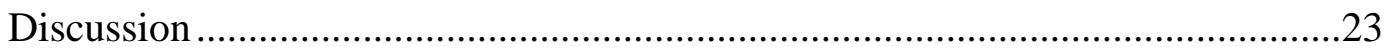

II EFFECTS OF LANDMARKS ON THE LANDSCAPE OF AGGRESSION............36

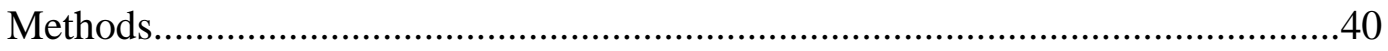

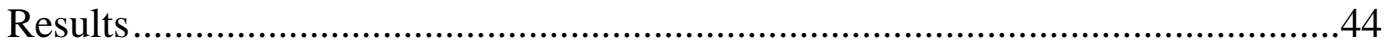

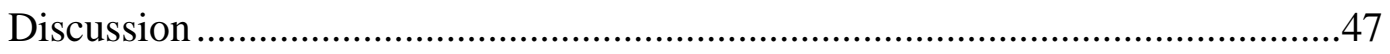

III EFFECTS OF LANDMARKS ON TERRITORY PROPERTIES .............................57

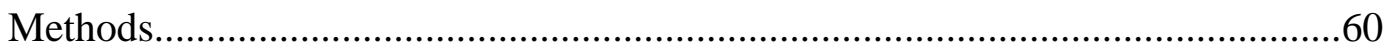

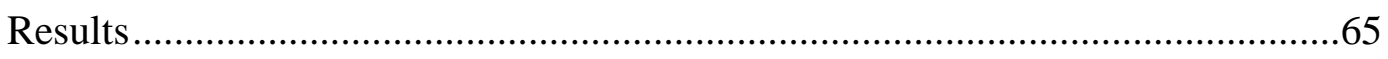

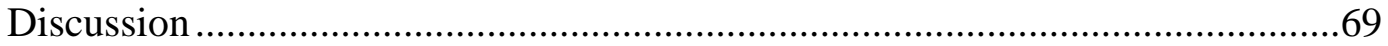

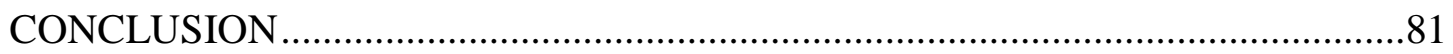


REFERENCES

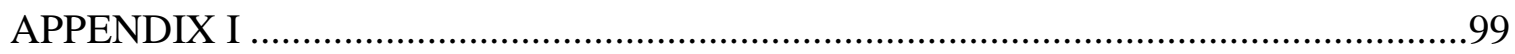

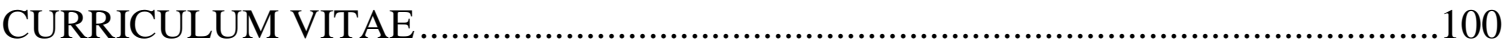




\section{LIST OF FIGURES}

1. Two treatments with different defensive costs

2a. Mean number of interactions that occurred at different locations of the tank in the buffer treatment.

2b. Mean number of interactions that occurred at different shell columns in the nobuffer treatment.

3. The percent time residents spent interacting with intruders under different defensive costs

4a. Percent time males spent interacting with intra- and intersexual intruders in buffer and no-buffer treatments

4b. Percent time females spent interacting with intra- and intersexual intruders in buffer and no-buffer treatments

5a. Percent of intruders that resident males and females interacted with in the absence

of a buffer zone

5b. Percent of intruders that resident males and females interacted with in the presence of a buffer zone .35

6. The mean distance between fish during face-offs

7a.The schematic diagram: Measuring the distance to face-off midpoint from the 
boundary

7b. Mean distance to face-off midpoint from the boundary ....................................53

8. Mean distance to the boundary from the endpoint of the chase .............................54

9a.The schematic diagram: Measuring the distance from the boundary midpoint to

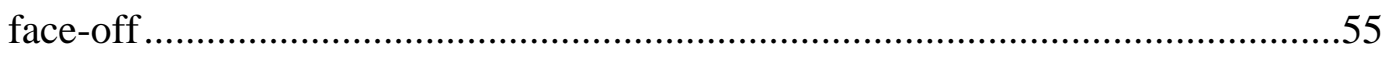

9b. Vertical distance from the boundary midpoint to face-offs ..................................55

10. Number of interactions that occurred at different locations of the boundary ........56

11. The size of territories observed in the survey with varying degree of landmark cover.

12. The shape of territories observed in the survey with varying degree of landmark cover. .75

13a. Scaled diagram of territories with no landmark and with the point landmark.....76

13b. Scaled diagram of territories without and with the linear landmarks .................76

14a. Territory shape with no landmark and with the point landmark ........................77

14b. Territory shape without a landmark and with the linear landmark ....................78

15a. Distance to the boundary from the nest, with no landmark and with the point landmark

15b. Distance to the boundary from the nest, with no landmark and the linear landmark 


\section{INTRODUCTION}

To date, territorial behavior has been described in animals belonging to a number of diverse taxa including sea anemones, limpets, polychaetes, insects, crustaceans, spiders, fish, frogs, salamanders, lizards, mammals and birds (Huntingford and Turner 1987). Defending a territory allows the owner to monopolize its resources including food, mates, mating sites and refuges. Territoriality is presumed to be one of the primary determinants of reproductive success and thus individual fitness (Brown 1964; Cleveland 1999; LaManna and Eason 2003). The study of territoriality is important for the development of a greater understanding of the evolution of the behavior itself and may lead to a better understanding of the evolution of other phenomena such as social systems, communication and reproductive strategies (Heap et al. 2012). Here, I briefly describe the progression of the study of territoriality and then explain how my research links with and fits into the general study of territorial defense.

The conspicuous nature of territorial interactions has attracted the interest of researchers for a long time. Although the observations of male birds defending space dates back to classical Greek civilization, it was not until 1868 that the study of territoriality was formally initiated. Bernard Altum, a German ornithologist, noted that birds tended to adjust the size of their territories to meet their ecological requirements (Goodenough et al. 2009). Eliot Howards rediscovered this principle and presented the

first modern study of territoriality, providing comprehensive descriptions of conspicuous 
defensive behavior in Old World warblers and buntings. Based on his observations he described the foundation and functions of territories in the book "Territory in Bird Life" published in 1920. Although subsequent studies of territorial behavior soon added other animal taxa to the list of territorial species, avian territoriality has always been more extensively studied. Later, researchers' interest shifted to studying the interspecific variation of territorial behavior (Hinde 1956), but due to the vast variation among taxa, it was difficult to formulate a general model that might apply to a wide range of species.

A significant shift in the field of territorial studies occurred with the introduction of economic theory into behavioral ecology. In 1964, Jerram Brown introduced the idea of economic defensibility of territories. In his paper he argued that 'the type of territoriality evolved in a species depends on the types of requisites for which competition exists and upon the degree to which they are economically defendable in terms of balance between advantages and disadvantages of such defense to individuals." This verbal concept was soon reformed as the now familiar cost and benefits graphical models of territoriality (Davies and Houston 1984).

Although Brown's economic theory of defensibility was designed with birds in mind, it has been identified as a global model that could apply to a wide range of territorial species. Hence, this model has been the foundation of a large number of recent studies of territorial behavior. The economic approach to territoriality breaks the behavior into potentially measurable costs and benefits, creating a number of hypotheses that could be tested under natural conditions. The introduction of economic theory thus led to an explosion in theoretical, experimental and sophisticated observational studies of territoriality. 
Earlier empirical studies of economic defensibility manipulated the benefits associated with territories (e.g., Gill and Wolf 1975; Carpenter et al. 1983; Eberhard and Ewald 1994), while more recent studies focus on identifying variables that can affect the costs associated with defense. The presence of established or familiar neighbors (Eason and Hannon 1994), visibility within the territory (Eason and Stamps 2001), topography of the territory (Eason 1994) and the presence of landmarks (Eason et al. 1999; LaManna and Eason 2003) have been identified as some of the primary factors that affect the defensive costs. Using economic theory as a basis, the research I present here addresses the effects of landmarked boundaries on territory defense. In particular, I investigate how landmarked boundaries affect both the landscape of aggression, i.e. the individual responses of residents, and fundamental territory properties such as size, shape and location of boundaries.

For my investigations, I used cichlid fish as a model system. Cichlids are freshwater teleosts belonging to the family Cichlidae in the order Perciformes. They differ from other teleosts by having both a single-opening of the nostrils on each side of the head and an interrupted rather continuous lateral line. In addition, the uniquely shaped otolith in the ear proper, absence of a bony plate at the bottom of the eye and the intestine departing from the left side of the stomach make cichlids a distinct group of fishes (Barlow 2000). The family Cichlidae arose nearly 160 million years ago in Gondwanaland (Stiassny 1991). The fracturing of Gondwanaland - about 150 million years ago- and the movement of African and South American landmasses - about 65 million years ago- led to the formation of all extant lineages of the family Cichlidae, which are distributed in Africa, South and Central America, and Asia (Stiassny 1994). 
Today, at least 1,650 species have been scientifically described, making it one of the largest vertebrate families. Since the earliest field studies conducted in the 1950's by Lowe-McConnell, cichlids have been the focus of numerous ecological, evolutionary and behavioral investigations due to their rapid speciation, unique feeding specializations, diverse mating systems, and their role as an important protein source in tropical countries (McKaye 1984). Cichlids also stand out as an excellent system for the investigations related to territoriality due to their well-known dramatic territorial displays and their willingness to defend territories both in the field and in the lab.

In my first chapter, I describe the sex differences in territorial defense in Neolamprologus multifasciatus, a shell-breeding African cichlid fish from Lake Tanganyika in East Africa. In most species in which males and females reside within a territory and defend it, both sexes presumably benefit from holding the territory (Quinard and Cezilly 2012). However, studies of territorial behavior have generally focused on agonistic interactions between individuals of one sex, usually males. Due to this bias in available literature, the respective roles that each gender plays in territorial defense are poorly understood. In this laboratory study, I examined resident pairs' responses to changes in defensive costs and to intruders of different genders. Studies have shown that defensive costs are lower when territorial boundaries are clearly defined (van den Assem 1967; Eason et al. 1999; LaManna and Eason 2003). Accordingly, to alter defensive costs I used two different distributions of shells: one in which territories were separated by a visually distinctive area, a defendable empty space without shells, and one without a visual gap. $N$. multifasciatus easily adapts to maintenance in aquaria and has many benefits as a species for behavioral ecology studies. Both males and females actively 
defend their territories and have unique stripe patterns that could be used for identification. They use shells as egg-laying sites, and refuges for fry and adults. A territory contains an average of 17.5 shells, typically places within a $20-50 \mathrm{~cm}$ depression of scooped out sand (Kohler 1997).

Findings of this laboratory study led to the development of the rest of the research mentioned in my dissertation. This study suggested that the resource-free space between territories can function as a visual landmark to reduce aggression between territorial neighbors. To understand how these visual landmarks affect territorial defense in natural conditions, I did field studies with Central American cichlid fish. The next two chapters of my dissertation describe the two field studies that I conducted at Lake Xiloá, a small caldera lake in Western Nicaragua.

Lake Xiloá is approximately 6100 years old (Meyer, in press), covers 360 ha, and has a maximum depth of $92 \mathrm{~m}$ (Riedel, 1964). Visibility within the lake averages 2-3m during dry season (November to May) and increases to 3-4m during wet season (Lim et al. 1976). Water temperature is fairly constant at $28^{\circ} \mathrm{C}$ during the dry season from the surface to approximately 25m (Barlow et al. 1976). Like many crater lakes, Lake Xiloá is oligotrophic with the flora dominated by an alga, Chara, belonging to family Characeae. The macroinvertebrate fauna consist of one species of crab, Potamocarcinus nicaraguensis, and numerous small snails whose shells make up a significant portion of the substrate. Besides fish, the other vertebrates in the lake are the frog, Smilisca baudini, and the turtle, Pseudemys scripta. The ichthyofauna of Lake Xiloá includes both cichlid and non-cichlid fishes. The 12 cichlid fish species are: Amatitlania siquia, Amphilophus rostratus, A. xiloaensis, A. amarillo, A. sagittae, Amphilophus sp. "flat lips", 
Archocentrus centrarchus, Astatoheros longimanus Cichlasoma citrinellum, Hypsophrys nicaraguensis, H. nematopus, Parachromis dovii, and P. managuense (Dittmann et al. 2012). The six non-cichlid fish species include: the catfish, Rhamdia nicaraguensis; the atherinid, Melaniris sardinia; the clupeid, Dorosoma chavesi; the molly, Poecilia sphenops; the swamp eel, Synbranchus marmoratus; and the eleotrid, Gobiomorus dormitor (Villa, 1968). The research I describe here was conducted off the lake's eastern shore at depths from $8-15 \mathrm{~m}$ in an area approximately $85 \mathrm{~m}$ in length. This site is characterized by a moderate slope, and the substrate is comprised of silt and sand.

In my second chapter, I examined the effects of landmarks on the landscape of space-partitioning agonistic interactions. Space-partitioning interactions that occur among contiguous neighbors or potential settlers determine the ultimate territory size or the density of territory owners (Stamps 1990; Adams 2001). Although these social interactions could be greatly affected by the presence of a visual landmark, its effects on the landscape of overall aggression has rarely been investigated. I observed the territorial behavior of Hypsophrys nicaraguensis, a cichlid fish native to Nicaragua and Costa Rica, in their natural habitat to understand how breeding pairs responded to the presence of landmarks. As the landmark, I used a plastic plant similar in form to the naturally occurring Chara sp. H. nicaraguensis is a good candidate for this study as fish of this species defend contiguous territories in the sandy habitat. The absences of distinct topographical features in the sandy habitat of the lake allowed me to conduct experimental manipulations to investigate fish responses to the presence of landmarks. In this study, I first addressed whether landmarks can affect the presence of defensive boundary zones. Second, I investigated whether landmarks were useful in precisely 
defining territory borders. Third, I tested if landmarks altered where agonistic interactions occured along the boundary that was being shared by both neighbors.

In the third chapter, I report observations on the territorial behavior of Amatitlania siquia, a convict cichlid native to Nicaragua and Costa Rica, in order to understand the effects of landmarks on territory properties such as territory size, shape and the flexibility of territorial boundaries. Although most theoretical and empirical work recognizes the significance of landmarks in lowering defensive costs, little attention has been given to identify its effects on territory properties. This field study consisted of two parts. First, I did a preliminary observational survey to identify whether territory properties varied with the presence of a landmarked boundary. Then, I manipulated convict territories to examine how they alter territory properties as a response to the presence of the landmark. In the experimental manipulation, I provided empty beer cans as breeding sites and used plastic plants similar in form to the naturally occurring Chara sp. in the lake as landmarks. Although convicts are considered the "white rat" of cichlids (Meral 1973), A. siquia is an understudied member of the convict group, due in part to its limited range. It is a good candidate for this study because the limited availability of suitable breeding sites disposes this substrate-brooding cichlid to rapidly colonize artificial breeding sites (personal observations). In addition, both males and females actively defend their territories from intruders. In my experimental study, I observed each pair with either one (point landmark) or four plants (linear landmark) and also without landmarks to determine whether these cichlids alter the size, shape and boundaries of their territories in response to landmarks. 


\section{CHAPTER I}

\section{SEX DIFFERENCES IN TERRITORIAL DEFENSE}

Although in many diverse territorial species both males and females defend the territory, their respective roles in that defense are poorly understood. Both sexes presumably benefit from holding a territory (Quinard and Cezilly 2012), but most studies of territorial behavior have focused on agonistic interactions between individuals of one sex, usually males. Males are typically more overtly aggressive (Maccoby and Jacklin 1974; Coie and Dodge 1997; Akin 1998; Draud et al. 2004; Fedy and Stutchbury 2005; Buss 2005), making their interactions easier to observe and study, and researchers have documented agonistic interactions between males in numerous vertebrate and invertebrate taxa (e.g. molluscs, Rollo and Wellington 1979; insects, Davies 1978, Alcock 1983; fish, Thresher 1979; amphibians, Jaeger et al. 1983, Kluge 1981; reptiles, Barker et al. 1979; birds, Foster 1981; mammals, Miller 1974). In contrast, females may tend to use more subtle ways to interact with one another, making their aggression more difficult to detect (Amundsen 2000). As a result, studies of female aggression are largely limited to the few species in which sex roles are reversed (Andersson 1994; BalshineEarn and McAndrew 1995; Petersen and Hardy 1996; Goubault et al. 2007). However, by focusing on one gender at a time, we can neither assess the relative contributions of males and females to defense nor understand how the members of a pair divide tasks or 
cooperate in simultaneous defense. Examining male and female defensive behavior simultaneously has the potential to answer such questions, and to enhance our understanding of the evolutionary forces underlying the sexes' tactics (Arnott and Elwood 2009).

One factor that is known to influence residents' responses during territorial defense is intruder gender. Many territorial birds and fishes display a strong, same-sex bias during defense, with males interacting with intruding males while females interact primarily with female intruders (Keenleyside et al. 1990; Levin 1996b; Bard et al. 2002; Harding et al. 2003). This difference in behavior may reflect size differences: by interacting with same-sex intruders, the smaller resident tends to interact with smaller intruders, leaving the larger resident to interact with larger intruders (Itzkowitz et al. 2005). However, in other cases, residents tend to interact with intruders of the opposite sex rather than with same-sex intruders (Logue and Gammon 2004), and in still others residents may defend the territory irrespective of the intruder's gender (Hand 1986; Busch et al. 2004). Residents may also follow gender-specific rules: in tawny owls (Otus scops), for example, males defend against intruders of either sex, but females defend only against same-sex intruders (Galeotti et al. 1997).

A second factor that may affect gender differences in territorial defense is the level of defensive costs. Changes in defensive costs can lead to the adoption of different tactics or behaviors during territory defense (Eason et al. 1999; LaManna and Eason 2003). However, there has been little research on how changes in costs might affect gender differences in territorial behavior. Defense when costs are elevated is likely to be critical for breeding success and thus an important component of territorial behavior. 
When defensive costs are higher, either both male and female or only one member of the pair could potentially increase their defensive efforts. One study did suggest that increased costs might result in more joint activities by resident pairs: increased simulated intrusions caused territorial magpie-larks (Grallina cyanoleuca) to increase the proportion of duet songs relative to solos (Hall 2000). Resident wintering Willow Flycatchers (Empidonax traillii) also responded strongly when defensive costs were elevated due to the increase in rate of intrusions by conspecifics (Sogge et al. 2007).

In this study, I first tested whether visually distinctive areas between territories lower defensive costs and then investigated resident pairs' responses to high and low costs and to intruders of different genders. I used Neolamprologus multifasciatus, a small, shell-inhabiting cichlid fish from Lake Tanganyika, as the study species. Studies have shown that defensive costs are lower when territorial boundaries are clearly defined (van den Assem 1967; Eason et al. 1999; LaManna and Eason 2003). Accordingly, to alter defensive costs I used two different distributions of shells: one in which territories were separated by a visually distinctive area, an empty space without shells, and one without a visual gap. I then compared males' and females' behaviors across treatments.

N. multifasciatus defend territories that contain empty Neothauma snail shells on sandy substrates in Lake Tanganyika. On average, there are 17.5 snail shells per territory (Kohler, 1997). These territories were created by digging shells out from the sand, and territories are separated from each other by sand removed from between the shells (Sato and Gashagaza 1997). Females use these shells to lay eggs. After reaching about 10mm, each fish occupies at least one shell (Schradin and Lamprecht 2000) and both adults and fry take shelter in these shells when threatened. N. multifasciatus is a colonial breeder, 
with colonies consisting of as many as closely related 20 individuals, with one to three adult males, one to five adult females, juveniles of both sexes, and numerous fry. Females primarily care for the eggs and larvae, by aerating them regularly (Kohler, 1997) while male provide no parental care for the young (Schradin and Lamprecht 2000). 


\section{METHODS}

\section{Laboratory Maintenance}

For this study, I used wild-caught $N$. multifasciatus provided by local fish importers. Fish were sorted by sex and housed in single-sex holding aquaria until they were used for experiments. Each housing aquaria contained several small clay pots for shelter. The aquaria were filled with tap water, treated to remove chlorine and chloramines, and kept at $26-28^{0} \mathrm{C}$. Each aquarium had two sponge filters and heaters symmetrically mounted in each rear corner, as well as ruler tapes affixed to the front and back for position measurements. Aquaria were maintained on a photoperiod of L:D 12:12 and fish were given flake food every other day. Males on average measured $41.6 \pm 0.5$ $\mathrm{mm}$ in total length while females were on average $36.6 \pm 0.4 \mathrm{~mm}$ in total length. All fish were used once.

\section{Fish Pairing}

For pairing fish, I used $38 \mathrm{~L}(50 \mathrm{~cm} \times 25 \mathrm{~cm} \times 30 \mathrm{~cm})$ aquaria with four Neothauma snail shells partially buried in sand. Since $N$. multifasciatus exhibit size-assortative mating in nature and are sexually dimorphic in size (Kohler 1997), fish were selected for pairing so that the male was 3 - $6 \mathrm{~mm}$ larger than the female.

I put one male and one female fish into a pairing tank and allowed the fish to interact. Fish were considered paired if they stayed together by shells, or spent time within one body length of each other without aggressive behaviors (Draud and Lynch 2002). All paired fish also exhibited behavior typical of mates, such as the female 
bending her body into an ' $\mathrm{S}$ ' shape when her mate approached (personal observations). When there were two pairs with similarly sized males and females, I moved them to experimental aquaria. Residents in trials differed from their same-sex neighbors by $2 \mathrm{~mm}$ or less in total length.

\section{Experimental Set-up}

I used Neothauma snail shells to create two treatments, one with high and one with low defensive costs (Fig 1). Each treatment contained 32 snail shells. For the low defensive cost treatment, I placed 16 snail shells in four by four grids on the left and right sides of a $110 \mathrm{~L}(76 \mathrm{~cm} \times 30 \mathrm{~cm} \times 45 \mathrm{~cm})$ aquarium. These two patches of shells were separated from one another by a visual gap, an area $15 \mathrm{~cm}$ wide that contained no shells. For the high-cost treatment, I evenly distributed 32 snail shells in the aquarium, so that there was no visually distinctive area. Before each trial, I placed two opaque dividers in the middle of the aquarium. I then placed one of the size-matched heterosexual pairs on each side of the aquarium and allowed the fish to acclimate for five days.

\section{Trials}

Before the beginning of trials, I observed the fish and their behavior for approximately 10 minutes to note their unique stripe patterns for identification purposes and to locate their preferred shell. I defined the preferred shells as the ones where residents spent at least $80 \%$ of their time during these observations. After removing dividers, I began the trial either when the first interaction occurred or when any individual crossed the midline of the aquarium. The mid-line was considered to be the 
territory boundary for determining when an intrusion occurred because in preliminary trials pairs used the center of the aquarium as the boundary (see also Results). I recorded residents' agonistic behaviors toward neighbors that intruded into their territory, and then divided these behaviors into two levels of aggression according to established hierarchies (Schradin and Lamprecht 2000; Bergmüller and Taborsky 2005; Hamilton et al. 2005; Pelletier 2008).

1) Mildly aggressive behaviors:

a) Dorsal fin flare: A fish erects its dorsal fin, spreads other fins or gills and displays.

b) Parallel swimming: Both fish synchronize their movements, but without flaring fins.

c) Nips: Very short interactions in which one fish approaches its opponent quickly and appears to nip at its body.

2) Highly aggressive behaviors:

a) Tail beat: Fish position themselves parallel to one another and push water at their opponent with their tails

b) Chase: One fish chases the other rapidly across the aquarium, often attempting to bite the target fish

c) Fight: Two fish bite at one another, often circling around and rolling in the sand and making a great deal of body contact.

d) Mouth lock: Two opponents lock their mouths together and push at one another violently. 
An interaction was defined as a single meeting between two fish even it included several aggressive displays. For each interaction, I recorded the gender of the fish involved, type of interaction, and its duration and location. I used percent time spent interacting with intruders and rates of high-level acts as estimates of defensive costs. Interactions in which both residents simultaneously interacted with an intruder were considered separately from interactions between a single resident and an intruder.

I used two rules to determine the end of a trial. First, if a fish was evicted from the territory and did not return to reclaim it for the next 30 minutes, I defined the end of the trial as the time when the fish left. Second, if no high aggressive behaviors occurred for 30 minutes, I ended the trial at the last occurrence of such aggression. Originally I had planned to include interactions for up to180 minutes, if no fish left and highly aggressive behaviors continued. However, for all trials, data collection stopped before 180 minutes using these two rules. I conducted 16 trials, eight for each treatment.

\section{Data Analysis:}

I used Anderson-Darling test to check whether data followed the normal distribution. I used a $\log (\mathrm{x}+1)$ transformation to normalize the rate of highly aggressive acts used by residents to interact with intruders with and without a visual gap. I then used an arcsine transformation to normalize the percent time resident females spent interacting with intruders of different genders, and a $\log (x+1)$ transformation to normalize the rate of highly aggressive acts used by males in two treatments. For all analyses, if the data were not normally distributed and standard transformations did not normalize them, I used nonparametric tests. All data analysis was carried out on Minitab 16 Statistical 
Software (2010), and means are reported \pm SE.

To investigate whether visually distinctive areas between territories lower defensive costs, I used two parameters; a) time spent in aggressive interactions; and b) the number of highly aggressive acts used in defense. To test these parameters I used ttests. I used another t-test to compare the average duration of trials with and without a visual gap. I then performed a second t-test to determine whether residents' rates of intrusion on their neighbors differed across treatments. A third t-test was used to examine whether the proportions of intruders with which residents interacted differed with and without the visual gap. I used a two-way ANOVA and follow-up Tukey tests to compare the percent time males and females spent interacting with intruders in the two treatments. To examine patterns of aggression in residents, I first performed a two-way ANOVA to compare the rate of mildly aggressive acts across treatments and resident gender; I compared rates rather than assessing numbers of acts because trials had different durations. I could not analyze highly aggressive acts in females because they seldom used such acts (see results), and accordingly I performed a t-test to compare percent of highly aggressive acts for males across treatments.

To investigate whether the location of the preferred shell affected residents' aggressive behavior, I performed Spearman rank correlations between the percent time males and females spent in defense and preferred shells' column numbers. I numbered columns of shells one to four, with column one the nearest to the boundary and four farthest from the boundary and thus adjacent to the aquarium's side. For males only, I also ran Spearman rank correlations on the columns of the preferred shells and the level of aggression males employed to interact with intruders. I did these correlations for both 
treatments. I also examined whether residents showed a preference for particular shell locations. For this test, I divided each territory into halves, the two columns of shells nearer the boundary versus the two columns farther from the boundary. I then performed Chi-square tests for males and females to determine whether preferred shells were more often located in one half than expected by chance.

To examine how intruder gender affected residents' responses, I used two-way ANOVAs, and follow-up Tukey tests if needed, to analyze the percent time males and females spent interacting with male and female intruders. I performed a t-test to determine whether residents interacted with different proportions of male and female intruders overall, and I then used t-tests to determine whether male and female residents differed in the percentages of same-and opposite-sex intruders with which they interacted. I performed a Pearson correlation analysis to examine whether the proportion of intrusions by male residents was correlated with the number of intrusions in each trial. Finally, for males, I used Mann-Whitney U tests to compare the rate of highly aggressive acts used against male and female intruders in the two treatments.

To determine whether male and female residents responded differently to increasing numbers of intrusions, I used Spearman rank correlations to test whether the percent of intruders they interacted with was correlated with the total number of intruders in trials with and without a visual gap. For this analysis, I counted only intruders chased by males or females and did not include intruders chased by both members of a pair. 


\section{RESULTS}

On average, trials in which a visual gap was present lasted $50.14 \pm 7.93 \mathrm{~min}$ (range: 18.31 - $78.08 \mathrm{~min}$ ), and trials without a visual gap lasted $32.90 \pm 9.01 \mathrm{~min}$ (range: $11.07-85.43 \mathrm{~min})$; this difference was not significant ( $\mathrm{t}$ test: $\left.\mathrm{t}_{(14)}=1.44, P=0.17\right)$. Of the eight trials without a visual gap, six ended because one or both members of a pair were evicted (four males, one female, and one pair were evicted); only three of eight trials with a visual gap ended due to eviction (three males). Overall, there were 1395 intrusions by residents into their neighbors' territories, with 987 intrusions by males and 408 by females. The total number of interactions with intruders in all trials was 1156 , with 430 in trials with a visual gap ( 292 by males, 115 by females and 23 by both) and 726 in trials without a visual gap (548 by males, 140 by females and 38 by both). In both treatments, pairs defended approximately a half of the aquarium (with the boundary at the center). In the visual gap treatment, a high proportion of aggressive interactions occurred along the mid-line of the tank (Fig. 2a), indicating that fish used it as their boundary. In the no-visual gap treatment, most of the interactions again occurred near the center of the aquarium (Fig. 2b) but were more widely dispersed.

Do visually distinctive areas between territories reduce defensive costs?

The presence of a visual gap significantly reduced the time residents spent in territorial defense ( $\mathrm{t}$-test: $\left.\mathrm{t}_{(14)}=2.82, P=0.023\right)$. With a visual gap, residents defended the territory $15.78 \pm 2.56 \%$ of their time while they increase their time in defense to $36.70 \pm 6.98 \%$ in the absence of a visual gap. Visually distinctive areas, also, had a 
significant effect on residents' aggression levels: with $1.61 \pm 0.77$ acts per minute were highly aggressive when there was no visual gap and only $0.15 \pm 0.04$ acts per minute were highly aggressive when a visual gap was present ( $\mathrm{t}$-test: $\left.\mathrm{t}_{(14)}=2.52, P=0.040\right)$.

Effects of visual gap and resident gender on territorial defense:

Residents intruded on their neighbors' territory less often when visual gaps were present ( $1.73 \pm 0.47$ intrusions per minute) than when they were not $(4.72 \pm 1.08$ intrusions per minute; $\mathrm{t}$ test: $\mathrm{t}_{(14)}=2.55, P=0.031$ ), and on average residents interacted with similar proportions of intruders across treatments (with visual gap: $79.76 \pm 2.23 \%$; without visual gaps: $80.97 \pm 3.74 \%$; $\mathrm{t}$ test: $\left.\mathrm{t}_{(14)}=0.28, P=0.787\right)$. A two-way ANOVA on treatment and gender showed that there was a significant interaction between these two factors $\left(F_{(1,28)}=6.66, n=8, P=0.015\right.$; Fig. 3$)$. The presence of a visual gap reduced time spent in territorial defense (Tukey test: $P<0.05$ ). Resident gender also influenced defense time (Tukey test: $P<0.05$ ), with male residents spending a higher percentage of time interacting with intruders than did females. With a visual gap, males defended the territory $10.42 \pm 1.94 \%$ of their time and females for $5.36 \pm 1.69 \%$ of their time. Without a visual gap, males spent $30.13 \pm 6.65 \%$ and females spent $6.65 \pm 1.29 \%$ of their time in defense. Thus when there was no visual gap males increased their defense time to a greater degree than did females.

Residents' rates of mildly aggressive acts did not differ significantly between treatments (two-way ANOVA: $F(1,28)=2.97, P=0.096$ ), but did differ with resident gender $(F(1,28)=8.23, P=0.008$.), with average rates higher in males (males: $2.07 \pm 0.43$ acts per minute; females: $0.74 \pm 0.21$ acts per minute). There was no significant 
interaction between treatment and gender $(F(1,28)=1.20, n=8, P=0.283)$. Visually distinctive areas between territories, however, had significant effect on males' aggression levels, with $39.27 \pm 0.11 \%$ of interactions highly aggressive when there was no visual gap and only $11.08 \pm 0.03 \%$ of interactions highly aggressive when a visual gap was present ( $\mathrm{t}$-test: $\left.\mathrm{t}_{(14)}=2.45, P=0.049\right)$. Statistical comparisons of highly aggressive acts by females were not possible because they performed such acts infrequently. Nine of the 16 females never acted highly aggressively, and the average rate of highly aggressive acts per female was $0.15 \pm 0.01$ without a visual gap and $0.08 \pm 0.04$ with a visual gap.

The percent time resident males spent in defense was not significantly correlated with the position of the preferred shell with respect to the boundary in either visual gap (Spearman rank correlation: $\mathrm{r}_{\mathrm{s}}=-0.330, n=8, P=0.181$ ) or no-visual gap treatments (Spearman rank correlation: $\mathrm{r}_{\mathrm{s}}=0.111, n=8, P=0.683$ ). Similarly, the position of the preferred shell was not significantly correlated with the percent time resident females spent in defense in either visual gap (Spearman rank correlation: $\mathrm{r}_{\mathrm{s}}=-0.162, n=8, P=$ 0.522 ) or no-visual gap treatments (Spearman rank correlation: $\mathrm{r}_{\mathrm{s}}=-0.028, n=8, P=$ 0.925). Females were more likely than expected by chance to prefer a shell in the half of the territory away from the boundary (Chi square test: $\chi^{2}=4.50, \mathrm{df}=1, \mathrm{P}=0.034$ ), but males were not (Chi square test: $\chi^{2}=1.88, \mathrm{df}=1, \mathrm{P}=0.172$ ).

\section{Effects of visual gap and intruder gender on territorial defense}

Intruder gender also affected the territorial behavior of $N$. multifasciatus. For male residents, a two-way ANOVA with time spent in defense as the response variable showed a significant interaction between treatment and intruder gender $\left(F_{(1,28)}=4.25, n=8, P=\right.$ 
0.049; Fig. 4a). Both intruder gender (Tukey test: $P<0.05$ ) and treatment (Tukey test: $P$ $=0.01)$ had a significant effects on time spent in defense. Males spent only $0.37 \pm 0.13 \%$ of their time in aggressive interactions with female intruders, but they increased the proportion of time they interacted with females to $2.58 \pm 0.95 \%$ when there was no visual gap, about a seven-fold increase. Males' interaction time with male intruders increased from $10.05 \pm 1.99 \%$ when there was a visual gap to $27.14 \pm 6.88 \%$ when there was not, a relatively smaller increase. Females similarly spent more time in interactions with samesex intruders (two-way ANOVA: $F(1,28)=6.08, n=8, P=0.020$; Fig. 4b). In contrast to males, however, in females there was no significant main effect for treatment on territorial behavior $(F(1,28)=0.97, n=8, P=0.334)$ and no significant interaction between treatment and intruder gender $\left(F_{(1,28)}=0.08, n=8, P=0.783\right)$.

Although the proportion of intruders with which the residents interacted was not significantly different across treatments (see above), overall residents interacted with a higher proportion of male intruders $(62.46 \pm 4.41 \%)$ than female intruders $(17.91 \pm$ $13.52 \%$; $\mathrm{t}$ test: $\left.\mathrm{t}_{(30)}=8.01, P<0.001\right)$. Males interacted with a significantly higher proportion of same-sex intruders $(71.64 \pm 4.95 \%)$ than did females $(33.38 \pm 4.64 \%$; $\mathrm{t}$ test: $\left.\mathrm{t}_{(30)}=5.64, P<0.001\right)$. However, the proportion of opposite-sex intruders chased by males and by females did not differ significantly ( $\mathrm{t}$ test: $\left.\mathrm{t}_{(30)}=0.85, P=0.403\right)$. Across all trials, the proportion of intrusions by males was positively correlated with the number of intrusions (Pearson correlation: $\mathrm{r}=0.543, n=16, P=0.030$ ).

As expected, intruder gender also influenced the level of aggression males used in interactions, with males more likely to use highly aggressive acts against males in both treatments. Without a visual gap, males performed highly aggressive acts against male 
intruders at an average rate of $1.44 \pm 0.69$ per minute and against female intruders at 0.02 \pm 0.02 per minute (Mann-Whitney $\mathrm{U}$ test: $\mathrm{U}_{(14)}=2, P=0.002$ ). With a visual gap, on average they performed $0.07 \pm 0.01$ highly aggressive acts per minute towards male intruders and $0.005 \pm 0.003$ highly aggressive acts per minute towards female intruders (Mann-Whitney U test: $\left.\mathrm{U}_{(14)}=0, P=0.001\right)$.

\section{Residents' responses to increasing numbers of intruders:}

To determine whether male and female residents responded differently to increasing numbers of intrusions, I tested whether the percent of intruders each gender interacted with was correlated with the total number of intruders in trials with and without a visual gap. When there was no visual gap, the percent of intrusions to which males responded was positively correlated with the number of intrusions (Spearman rank correlation: $\mathrm{r}_{\mathrm{s}}=0.762, n=8, P=0.028$; Fig. 5a), but for females those two variable were negatively correlated, although this trend was not significant (Spearman rank correlation: $\mathrm{r}_{\mathrm{s}}=-0.333, n=8, P=0.420$; Fig. 5a). In the presence of a visual gap, neither male (Spearman rank correlation: $\mathrm{r}_{\mathrm{s}}=0.275, n=8, P=0.509$; Fig. 5b) nor female (Spearman rank correlation: $\mathrm{r}_{\mathrm{s}}=-0.048, n=8, P=0.910$; Fig. $5 \mathrm{~b}$ ) interactions were significantly correlated with an increasing number of intrusions. 


\section{DISCUSSION}

Differences in overall defensive costs and intruder gender affected how male and

female $N$. multifasciatus defended their territories. In the presence of a visual gap, an area between territories without structural landmarks or resources, defensive costs for the resident pair were lower, as estimated by a) time spent in aggressive interactions; and b) the number of highly aggressive acts used in defense.

It is arguable, that the increased inter-territorial distance in visual gap treatment may have contributed to the decrease in interactions. However, the fish in the visual gap treatment clearly defended the empty space, and a high proportion of aggressive interactions occurred at its center. In contrast, in the no-visual gap treatment, aggressive interactions were more widely distributed across the central third of the aquarium, suggesting that the territorial boundaries may have been less precisely defined. Thus the shell-free space between territories might have resulted in fewer intrusions, by acting as a visual landmark that reduced defensive costs. When boundaries between territories are well defined, inadvertent intrusions into neighboring territories may decline (Stamps 1998; Eason et al. 1999; LaManna and Eason 2003). Individuals may also be less able to identify when a rival has entered their territory when boundaries are indistinct (Eason et al. 1999). Accordingly, territory holders may more frequently approach their territorial borders, which would tend to increase the frequency of aggressive interactions between neighbors (Eason and Hannon 2003). Territory boundaries are often demarcated by distinct, naturally occurring (Welsh 1975; Craig 1979; Hixon 1981; Reid and Weatherhead 1988) or man-made (Ficken 1962; Potter 1972; Eason et al. 1999; LaManna 
and Eason 2003) landscape features or by a specific signal such as scent marks or scratched substrates (Gosling and Roberts 2001; Lewis and Moorcroft 2001, 2006; Hamelin and Lewis 2010). However, the current study differs from earlier work in that the absence of a structure created a discontinuity that formed the territorial boundary. This study is the first to suggest that the absence of a structure or a resource-free space between territories can be used as a visual landmark.

In this study, the decrease in defensive costs associated with the presence of a visual gap between territories was mainly driven by fewer intrusions by residents into the neighboring territory. Pairs interacted with the same proportion of intruders in both treatments regardless of the rate of intrusions, and pairs spent more time in defense when intrusions were more frequent. Males were more sensitive to the effect of increased defensive costs. They spent a relatively greater amount of their time interacting with intruders when no visual gap was present than did females and increased the use of highly aggressive acts. Males also interacted with an increasing proportion of intruders as the number of intruders increased. In contrast, females did not significantly increase the time they spent interacting with intruders when there was no visual gap, rarely used energetically costly, highly aggressive acts to interact with intruders, and did not increase the proportion of intruders with which they interacted as intrusions increased. It should be noted, however, that this study examined behavior during territorial establishment; females might have shown higher aggression levels after laying eggs or after offspring hatched (Itzkowitz and Nyby 1982; Itzkowitz 1985; Desjardins et al. 2006). The different responses of males and females could have been due to the increases in intrusions being driven mainly by male intruders, given that male residents were more likely to interact 
with male intruders than were females. Males' increased tendency to intrude may reflect their possibility of attracting an additional mate.

The aggressive behavior of residents may also be affected by the location of preferred shell in the territory. Arguably, if the preferred shell is near the territory boundary, rather than toward the interior of the territory, the resident might interact more frequently with intruders due to spending more time near the boundary (Eason and Hannon 2003). However, in this study, the position of the preferred shell was not significantly correlated with the time resident males and females spent in defense nor with the level of aggression males used in interactions with intruders. A gender-related shell preference was observed only in females, which preferred shells in the half of the territory farther from the boundary. Females may reduce their interactions with intruders by spending more time far from the boundary. Alternatively, this preference could be linked to the offspring care provided by the female. In Lamprologus toae, another Lake Tanganyika cichlid, males mainly defend the peripheral area of the territory, while females defend the inner area, allowing one parent, the female, to stay near the young all the time (Nakan \& Nagoshi 1990). This division of roles in defense observed in L. toae enhanced brood protection. Such clear division was not seen in N. multifasciatus, however, as males did not have a significant preference for a particular half of the territory.

In general, males spend much of their time defending territories while females care for offspring (Smith-Grayton and Keenleyside 1978; Itzkowitz 1984; Wisenden 1994). Here I found that, relative to males, females make a smaller but still substantial contribution to territorial defense, particularly when overall defensive costs are low. 
Females spent about $5 \%$ to $6 \%$ of their time in defense with and without a visual gap. Some other studies have found that even males often spent relatively small percentages of their time in defense, with males of varied species defending territories $0.25 \%-10 \%$ of their time (fish, Craig 1996, LaManna and Eason 2003; birds, Salomonson and Balda 1977, Hixon et al. 1983; mammals, Smith 1968, Zegers 1981), which suggests that females' contribution can be significant. In our study species, females with young may shift their attention to offspring care and brood defense. Female contributions might thus be greater during the early stages of territorial establishment and defense, when I observed them. Alternatively, it is possible that female defense is significant in other species but has generally been overlooked because of the often more obvious behavior of males.

Previous studies suggested that intruder gender may also influence territorial behavior of individuals (Levin 1996b; Bard et al. 2002; Harding et al. 2003). Intrasexual aggression was much more frequent than intersexual aggression in N. multifasciatus territorial pairs. Intruder gender also influenced the level of aggression males used during interactions, with males more likely to use highly aggressive acts against males than female intruders. These observed gender differences in territory defense may be largely driven by differing selection pressures on each sex. Greater intrasexual aggression is not surprising for males, as the loss of a territory is very likely to decrease their fitness. On the other hand, if intruders are of the opposite sex, the male territory holder is unlikely to be threatened by eviction (Levin 1996b; Morton and Derrikson 1996; Appleby et al. 1999) and might even benefit from polygamy (Galeotti et al. 1997). Schradin and Lamprecht (2002) concluded that the increased female intrasexual aggression observed in 
wild populations of $N$. multifasciatus could have driven by the competition for snail shells. In a similar species, Lamprologus ocellatus, females competed intrasexually for shells and showed strong territoriality to the point that a smaller female was not able to settle near a bigger one even when snail shells were not limiting (Brandtmann et al. 1999). The presence of another female near the resident female's spawning site may result in her having to share the protection provided by the male to territory and offspring.

This study provides a base for developing an understanding of gender differences during territorial defense and also suggests new avenues for investigation into the nature of territorial boundaries. Females only slightly increased their territorial behavior when the defense became more costly, suggesting that at least in some species females' contribution to territory defense may vary relatively little regardless of overall costs. This could be tested by manipulating defensive costs to a greater degree, or through field studies on species in which wide variation in costs already exist. This study also suggests that an investigation of how females modify their territory defense prior and after the arrival of offspring would be useful to understand females' degree of flexibility in territorial behavior, overall contributions to territorial defense, and priorities and energy allocation under different circumstances. In fish (Chellappa et al. 1989; Smith and Wootton 1995, 1999), as well as in other taxa (Riechert 1988; Marler and Moore 1989; Hack 1997; Spence and Smith 2006), even a relatively short territorial contest or other aggressive interaction can be energetically costly. Hence selection would favor individuals who accept a resource-free visually distinctive area as a designator of a territory boundary. Utilizing such visual gaps to separate territories could also be 
applicable for animal welfare, through managing aggressive behavior in captivity. Future work should address whether individuals fight more intensely at the visual landmarks or avoid interacting there, as well as investigate how boundary areas without resources are defended in the field. Such boundaries commonly occur among, for example, birds that feed in savanna trees, hummingbirds defending multiple patches of flowers, and lizards defending rock piles. 

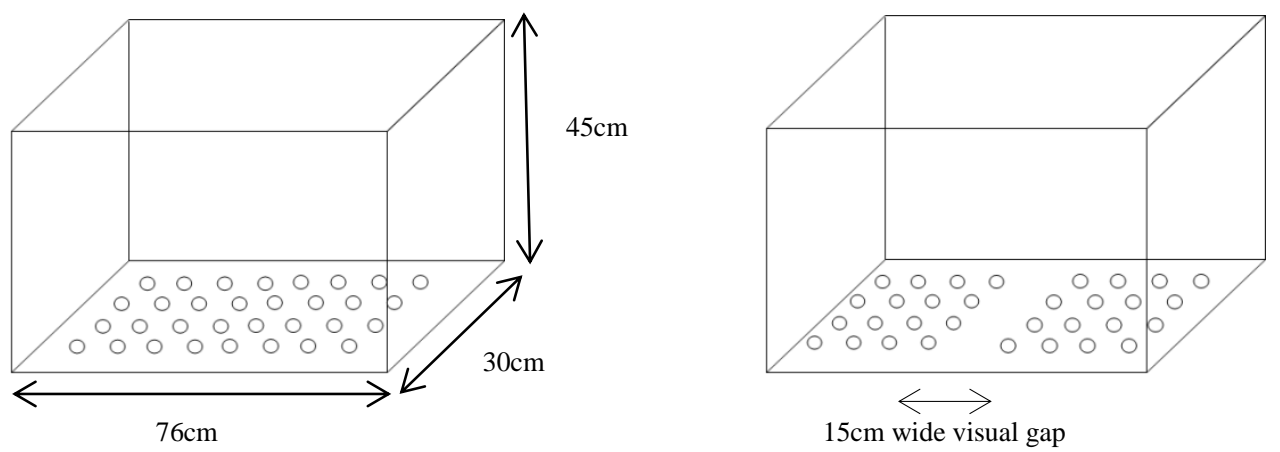

Figure 1: Two treatments with different defensive costs.

Left: High defensive cost treatment with no visual gap. Right: Low defensive cost treatment with a visual gap. The empty snail shells are represented by circles. 


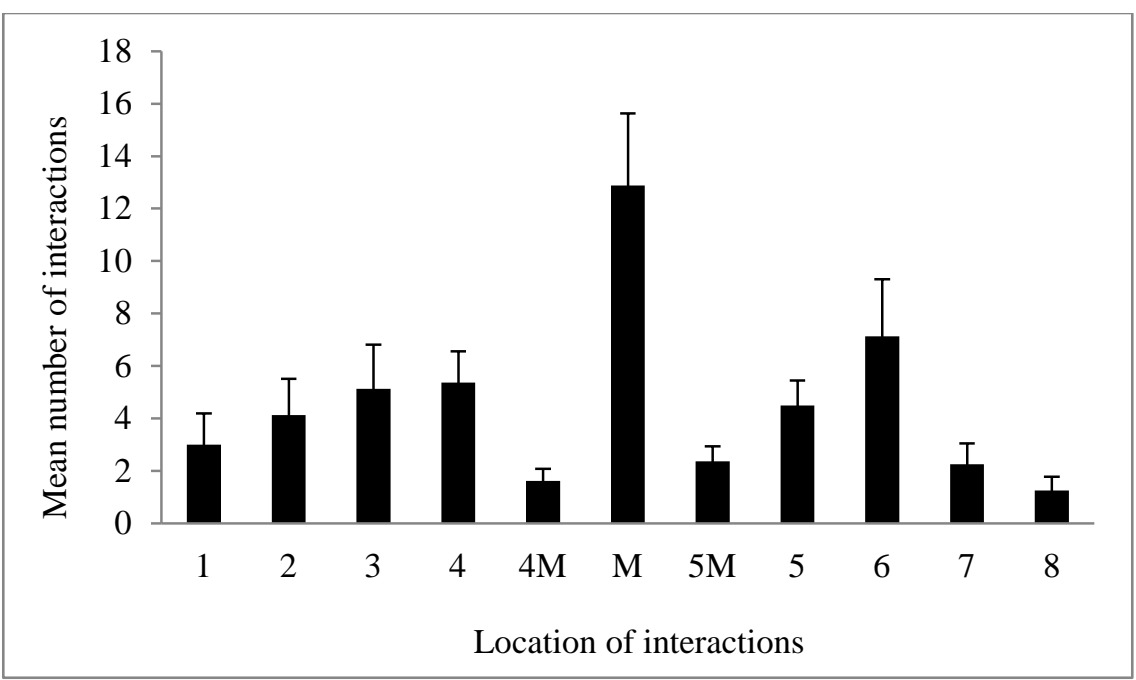

Figure 2a: Mean number of interactions that occurred at different locations of the tank with the visual gap.

Error bars indicate the standard error.

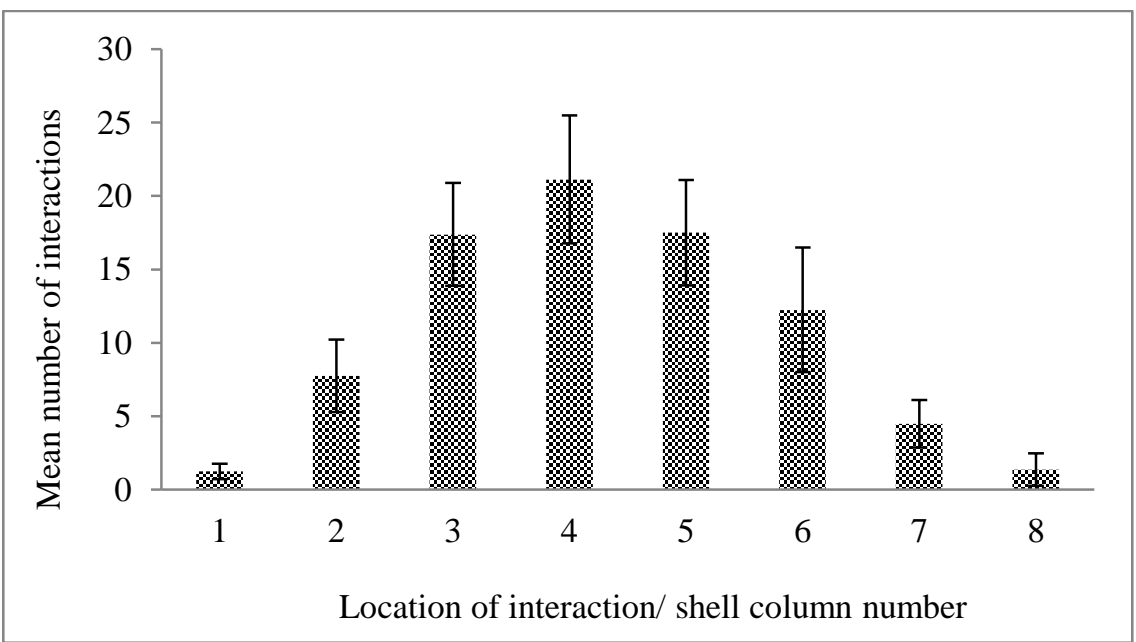

Figure 2b: Mean number of interactions that occurred at different shell columns in the no-visual gap treatment.

Error bars indicate the standard error. 


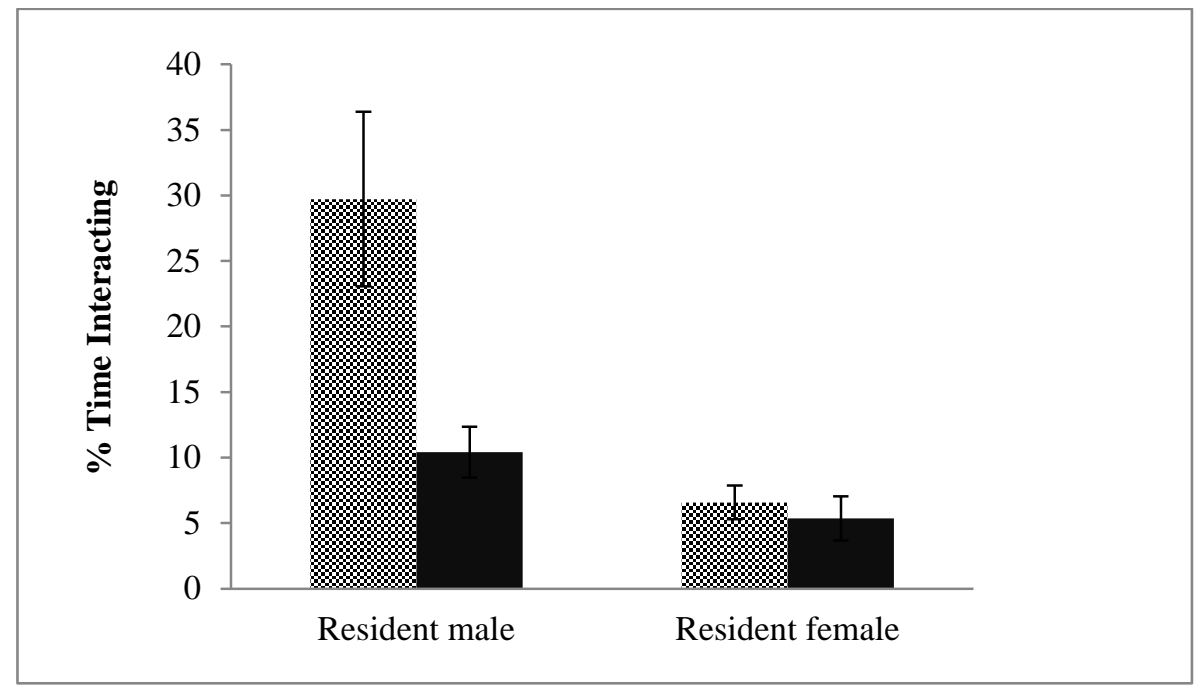

Figure 3: The percent time residents spent interacting with intruders under different defensive costs.

The presence of a visual gap reduced time spent in territorial defense, and males spent a higher percentage of time interacting with intruders than did females (two-way ANOVA: $\left.F_{(1,28)}=6.66, \mathrm{n}=8, P=0.015\right)$. Light and dark bars indicate no visual gap and visual gap treatments, respectively. Error bars indicate the standard error. 


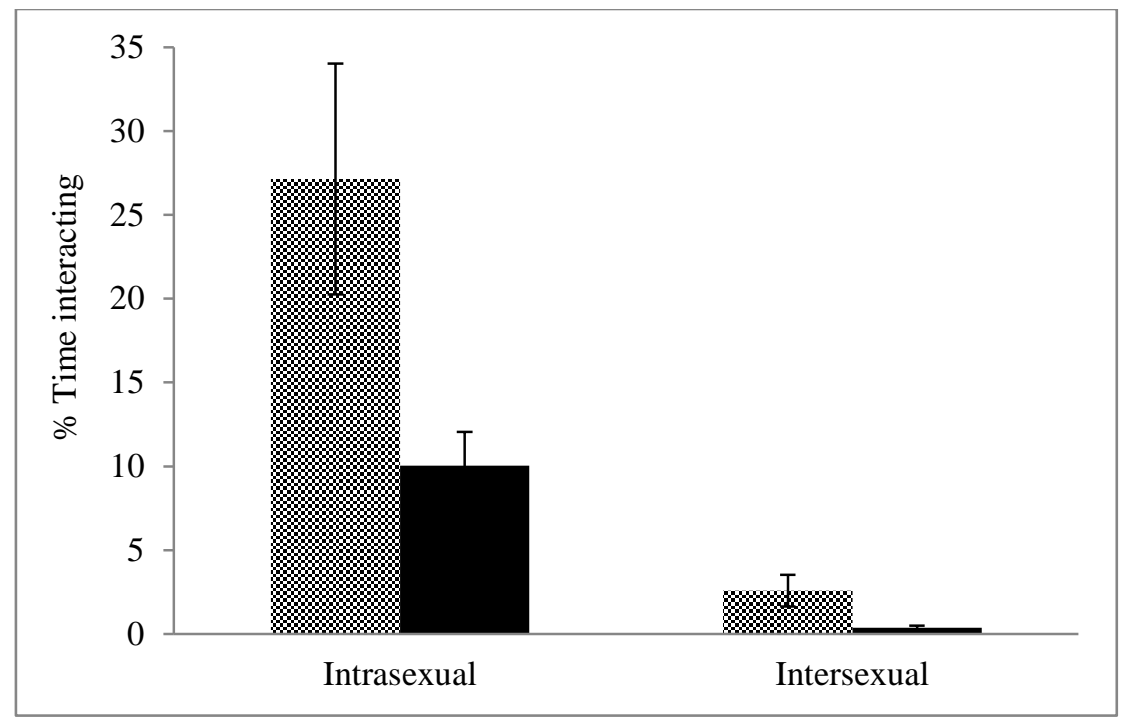

Figure 4a: Percent time males spent interacting with intra and intersexual intruders in visual gap (dark bars) and no-visual gap (light bars) treatment.

The presence of a visual gap reduced time spent in territorial defense, and males spent a higher percentage of time interacting with intruders than did females (two-way ANOVA: $\left.F_{(1,28)}=6.66, \mathrm{n}=8, P=0.049\right)$. Error bars indicate the standard error. 


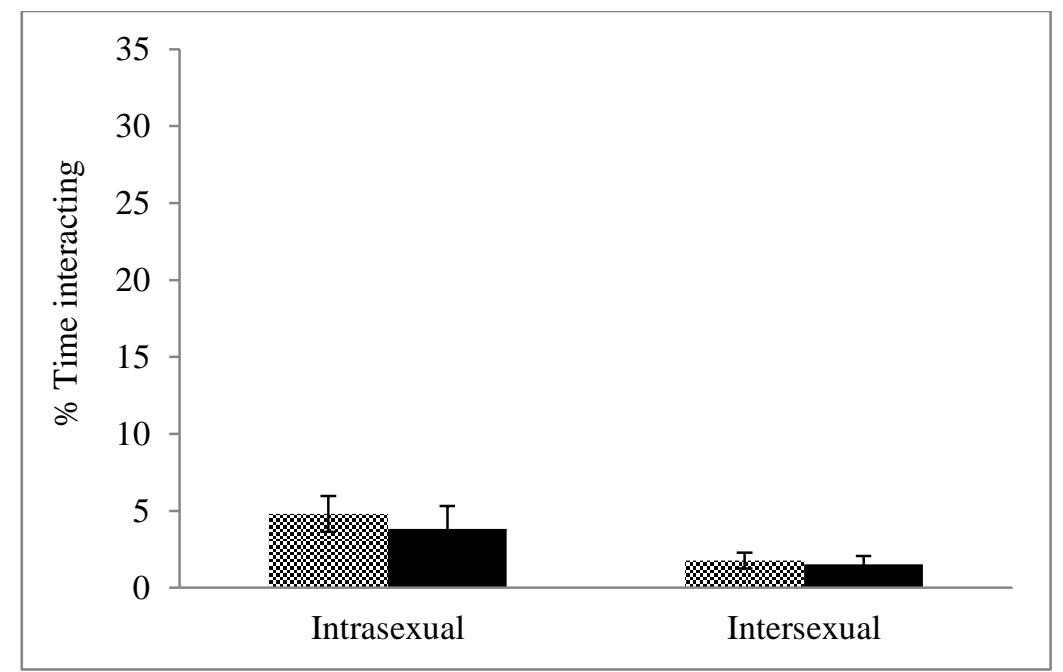

Figure 4b: Percent time females spent interacting with intra and intersexual intruders in visual gap (dark bars) and no-visual gap (light bars) treatment.

Females spent more time interacting with same-sex intruders but there was no significant interaction between treatment and intruder gender $\left(F_{(1,28)}=0.08, \mathrm{n}=8, P=0.783\right)$. Error bars indicate the standard error. 


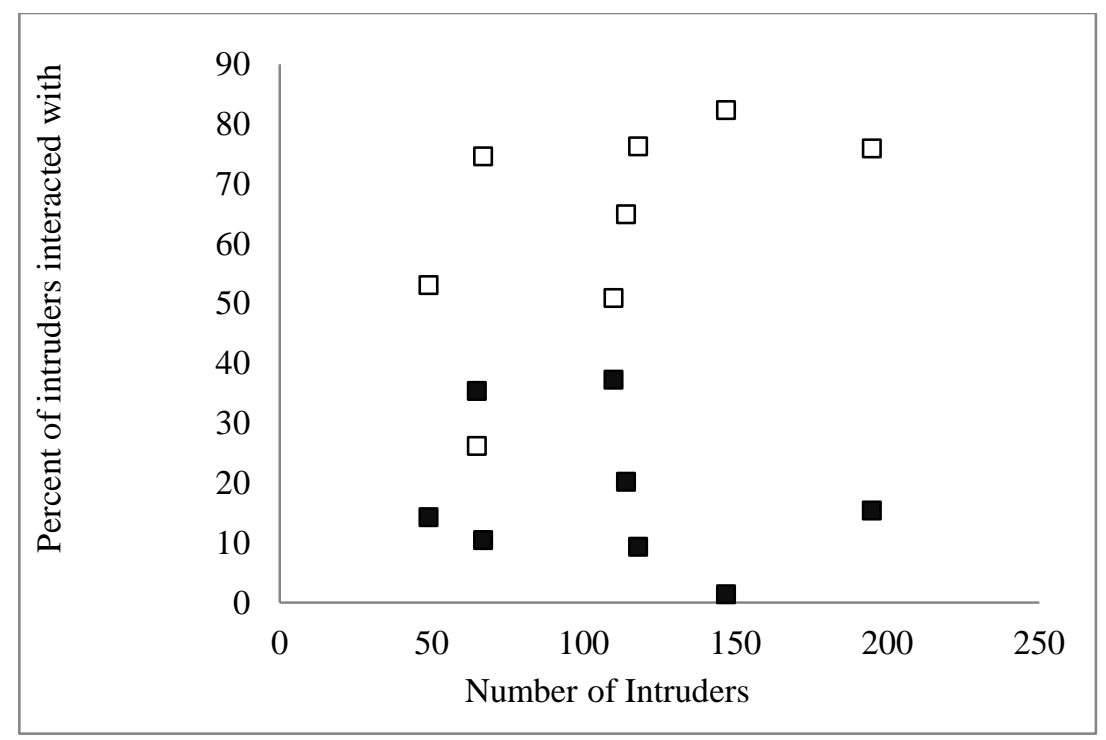

Figure 5a: Percent of intruders that resident males (open squares) and females (filled squares) interacted with in the absence of a visual gap.

The percent of intruders that males interacted with increased as the total number of intruders increased (Spearman rank correlation; $\mathrm{r}_{\mathrm{s}}=0.762, n=8, P=0.028$ ), but the percent that females interacted with was negatively correlated, although the effect was not significant (Spearman rank correlation; $\mathrm{r}_{\mathrm{s}}=-0.333, n=8, P=0.420$ ). 


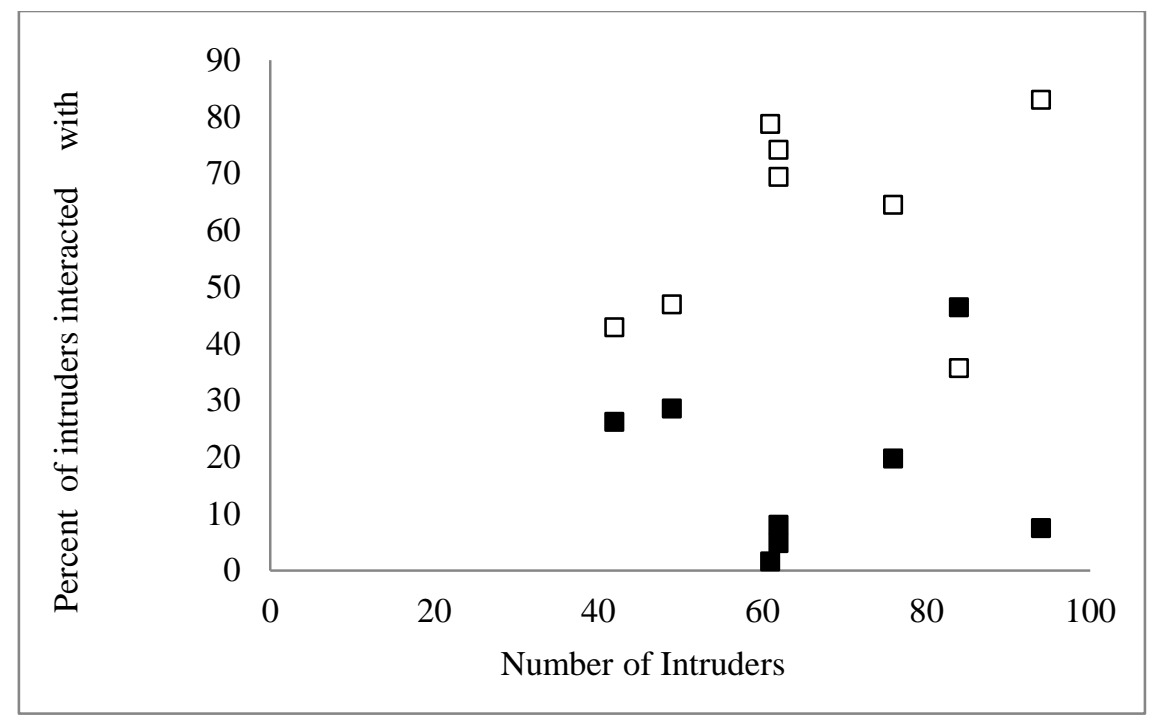

Figure 5b: Percent of intruders that resident males (open squares) and females (filled squares) interacted with in the presence of a visual gap.

There was no significant relationship between the number of intruders and the percent of intruders with which resident males (Spearman rank correlation; $\mathrm{r}_{\mathrm{s}}=0.275, n=8, P=$ 0.509 ) or females (Spearman rank correlation; $\mathrm{r}_{\mathrm{s}}=-0.048, n=8, P=0.910$ ) interacted. 


\title{
CHAPTER II
}

\section{EFFECTS OF LANDMARKS ON THE LANDSCAPE OF AGGRESSION}

\author{
Although the defense of a territory is one of the primary determinants of \\ reproductive success and thus of individual fitness (Brown 1964; Eberhard and Ewald \\ 1994; Keeley 2000), this behavior can be costly to the territory holder. Hence, territory \\ owners display a variety of behaviors that apparently serve to reduce defensive costs. One \\ means of reducing defensive cost is to select a site that has clearly delineated borders. A \\ number of previous studies suggest that many territorial animals tend to establish \\ territories so that boundaries are situated at conspicuous landmarks (Kodric-Brown 1978; \\ Kruuk 1978; Reid and Weatherhead 1988; Eason et al. 1999; LaManna and Eason 2003). \\ In certain species territorial individuals may themselves construct landmarks. For \\ example, male Boddart's goggle-eyed goby (Boleophthalmus boddarti) delineates the \\ polygon-shaped territories by erecting mud walls around the margins (Clayton 1987). In \\ addition, although the idea has yet to be formally tested, many nest and bower-building \\ cichlid fishes may similarly use the extensive excavations they undertake as boundary \\ markers.
}

Two hypotheses have been proposed to explain the adoption of landmarks to define territorial boundaries; the unilateral advantage hypothesis and the landmarks as conventions hypothesis. The unilateral advantage hypothesis predicts that individuals will 
be benefited from adopting landmarks, irrespective of whether rivals themselves use them, because landmarks make it easier for a resident to detect when an intruder crosses the boundary, hence avoiding unnecessary conflict (Eason et al. 1999). Alternatively, the convention hypothesis suggests that landmarks could act like conventions for territory partitioning, allowing neighbors to rapidly coordinate and mutually settle on a boundary position to avoid the costs associated with fighting or displaying, even to the detriment of one of them (Mesterton-Gibbons and Adams 2003).

Although a number of recent studies identify the significance that landmarks could have on individuals by lowering defense costs (see Heap et al. 2012 for review), their effects on the landscape of overall aggression have rarely been investigated. The space-partitioning interactions of contiguous neighbors or potential settlers determine the ultimate territory size or the density of territory owners (Stamps 1990; Adams 2001), and thus the population dynamics of territorial species (Morrell and Kokko 2005). However, these social interactions of territorial individuals could be greatly affected by the presence of visual landmarks. Landmarks are capable of reducing the frequency of aggressive interactions, the rate of territorial displays (Smith 2011; LaManna and Eason 2003) and the intensity level of fights (LaManna and Eason 2003). These behavioral adjustments of space use in response to the presence of a landmark can exert strong effects on the overall population dynamics of territorial species. Hence, an understanding of the role of landmarks in animal contests provides a link between behavioral decision-making and population dynamics, which has been viewed as a major goal in ecology (Kokko and Sutherland 1998; Smith et al. 2000a; 2006). 
In this field study, I examined the territorial behavior of Hypsophrys nicaraguensis neighbors to understand how they would alter the space partitioning interactions as a response to the presence of a landmark. H. nicaraguensis is a substratebrooding cichlid native to Northern Costa Rica and Nicaragua. In this sexually dimorphic cichlid fish, an adult male is $15 \mathrm{~cm}$ in total length while an adult female is $8.5 \mathrm{~cm}$ in total length. These bi-parental breeding pairs dig one or more holes in sand to create a nest in which to lay the eggs. They defend the area around it as the territory. Both the male and the female are needed to successfully defend territories in their natural habitat (McKaye 1977). H. nicaraguensis is a good candidate to investigate effects of landmarks as they defend territories in the sandy habitat. The sandy habitat of the study site lacked distinct topographical features that could potentially be used as landmarks. Hence, this species is ideal subject to investigate effects of landmarks by experimental manipulations. Size and sexual dimorphism of $H$. nicaraguensis facilitates the accurate identification of individuals during observations. In addition, due to the limited availability of breeding substrates, their territories are contiguous and are readily available during breeding season.

This study addressed three main questions.

1. Do landmarks affect the presence of defensive boundary zones?

2. Do landmarks increase the precision of territory boundaries?

3. Do landmarks affect the location of agonistic interactions?

I defined defensive boundary zone as an area in the territory that the territory resident is still capable of defending, but functions as a buffer zone to reduce the 
aggression between contiguous neighbors. In order to understand how landmarks affected the overall landscape of aggression, I observed the agonistic interactions that occurred across the boundary that was shared by two conspecific neighboring pairs. 


\section{METHODS}

Study Site

The study was conducted in Lake Xiloá, Nicaragua, in December 2012 using SCUBA. Experimental manipulations were conducted along the lake's eastern shore at depths from $8-15 \mathrm{~m}$ in an area approximately $50 \mathrm{~m}$ by $30 \mathrm{~m}$. This site is characterized by a moderate slope, and the substrate is comprised of silt and sand, lacking any distinct topographical features. As landmarks, I used plastic plants that were $6 \mathrm{~cm}$ wide and similar in form to the naturally occurring Chara sp. in the lake. Fish swam through these open-branched plants to chase intruders, indicating that they did not block the visibility or the fish's swimming.

\section{Experimental Manipulation}

First, I did a control experiment $(\mathrm{N}=26)$ to determine whether the landmark I selected altered pairs' use of space. Once I located a H. nicaraguensis breeding pair, I observed their behavior for 5 minutes to identify their territory boundary. I used chase locations to outline the boundary, with the location of the chase considered to be the position of the intruder when the resident initiated the chase (Breau and Grant 2002). Then, I selected an area within the territory that was $20 \mathrm{~cm}$ in diameter and I placed the plant at the center of it. This selected area was away from both the breeding site and the boundary. In two five-minute focal periods, I recorded the number of times the breeding pair visited this selected area with and without the plant. With each breeding pair, I 
alternated which treatment occurred first and performed the second treatment after the first, with a one-minute break to remove or place the plant.

For the experimental manipulation, I first located two adjacent breeding pairs of H. nicaraguensis and observed their behavior for five minutes to identify the chase locations of intruders (see above). These locations were marked on a scaled map of both territories to outline the borders of the territories. Once the territory boundary was identified, I recognized the midpoint of the shared boundary, at which the plastic plant was placed. I observed neighbors' agonistic behavior across the shared boundary for ten minutes, with $(\mathrm{N}=38)$ and without the plant $(\mathrm{N}=38)$. I alternated which trial occurred first and performed the second trial immediately after the first.

During this observation period I recorded face-offs that occurred between neighbors and sketched the path of intruders chased. In a face-off, a challenging behavior, two fish always participate, moving towards one another and then stopping, sometimes backing away and repeating their movements. The midpoints of face-offs are useful to identify the territory boundary because the two fish performing a face-off at a boundary would do so at approximately equal distances from the boundary (LaManna and Eason 2003). To determine where a face-off occurred, I marked the locations at which the two fish involved in the face-off stopped.

At the end of the 20-minutes of observation, I measured the distance between breeding holes in two territories. I also measured the length and width of each territory. Length was considered to be the greatest distance between territory boundaries while the territory width was considered as the greatest distance between boundaries perpendicular to the length. To estimate the sizes of breeding pairs, I placed a plastic ruler by each 
breeding hole, and waited until a fish aligned itself against it to read the closest measurement. The developmental stage of offspring was also noted and they were grouped into three categories as egg/wrigglers, fry and juveniles. Wrigglers are newly hatched offspring with the yolk sac and poorly developed fins (Wisenden and Dye 2009). The next free swimming stage is called fry. They are four to six weeks of age and two to seven millimeters in length. After the second week of fry stage, parents may begin to lead the brood away from the nest (McKaye 1977). The free-swimming juvenile stage, or the age at which the offspring are no longer actively protected by the parents, is usually achieved by the fourth or fifth week post-hatching. All the pairs that were observed in the study belonged to the pre-migratory stage as they were found at the nest. I also recorded the approximate length of fry when present. I marked all the observed territories with yellow survey flags to prevent resampling; in addition, individuals vary widely in pattern, making resampling unlikely. All observations were made at a distance of one to two meters away from focal fish.

\section{Data Analyses}

In the control experiment, to determine whether the landmark I selected altered fish's use of space, I did a Wilcoxon signed-rank test.

To determine the presence of defensive boundary zones, I measured the distance between two fish involved in face-offs with and without the landmark. For each trial, I calculated the mean distance between fish during face-offs and compared it with and without the landmark. To investigate whether landmarks are useful in precisely defining territory borders, I used two different parameters: the distance to the boundary from the 
midpoints of face-offs (Fig. 7a) and the distance intruders were chased beyond the shared boundary. To determine the variation of midpoint in face-offs, I selected face-offs with similar lengths $(-0.3 \mathrm{~cm})$ from both treatments and compared the mean distance to the boundary from face-off midpoints with and without the landmark. In addition, for each trial, I calculated the mean distance intruders were chased beyond the boundary and compared it with and without the landmark. I also examined whether the distance intruders were chased were correlated with the developmental stage of offspring. To estimate relative location of interactions, I used two measurements. First, I identified the midpoint of the shared boundary, which is the site where I placed the plant, and measured the vertical distance to each face-off from this midpoint (Fig. 9a). Then, I calculated the mean of this distance for each trial and compared it with and without the landmark. Second, I compared the number of interactions that occurred across different $30^{\circ}$ sections of the boundary. I drew a line between neighbors' nests, which I considered to be at $0^{\circ}$. Then I counted the number of chases in the three $30^{\circ}$ sections: $\pm 15^{\circ}, 15^{\circ}$ to $45^{\circ}$, and $-15^{\circ}$ to $-45^{\circ}$ from the nest.

I used Mann-Whitney U test to compare the mean distance to the boundary from the face-off midpoint with and without a landmark. Spearman rank correlation was used to test whether the offspring stage was correlated with the distance that intruders were chased. To compare the number of interactions that occurred across different $30^{\circ}$ sections of the boundary, I used a chi-squared test. I used Wilcoxon signed-rank tests for all the remaining analyses.

All data analysis was carried out on Minitab 16 Statistical Software (2010), and all means are reported \pm SE. 


\section{RESULTS}

The average length of a $H$. nicaraguensis territory was $89.64 \pm 4.73 \mathrm{~cm}$ while the average width was $70.62 \pm 4.02 \mathrm{~cm}$. The average distance between nests that belonged to two adjacent neighbors were $1.00 \pm 0.05 \mathrm{~m}$. Males were $14.3 \pm 0.22 \mathrm{~cm}$ in total length on average, while females were $8.87 \pm 1.40 \mathrm{~cm}$ in total length. Out of 38 pairs that I observed, $7.9 \%$ of them did not yet have eggs, $65.8 \%$ had eggs or wrigglers in their breeding sites, $18.4 \%$ had free swimming $1-2 \mathrm{~mm}$ long fry while the remaining $7.9 \%$ had fry larger than $4.5 \mathrm{~mm}$. In all trials, the total number of face-offs that occurred between conspecific neighbors across the shared boundary was 321 with 119 in trials with the landmark and 102 in trials without the landmark. Overall, residents were involved in 361 intruder chases, with 187 chases with the landmark and 174 without the landmark.

The control experiment demonstrated that the plant did not affect the pattern of space use of territory holders when it was placed within the territory (Wilcoxon signedrank test: $\left.\mathrm{W}_{(23)}=94.5, \mathrm{Z}=-1.323, P=0.191\right)$. With the plant present, fish visited the randomly selected area $5.85 \pm 0.66$ times per trial, and without the plant, the number of entries to the same area was $6.42 \pm 0.61$ per trial.

Do landmarks affect the size of defensive boundary zones?

Landmarks affected the amount of space between neighbors during aggressive interactions. With the presence of a landmark, the mean distance between fish during face-offs was $21.70 \pm 1.82 \mathrm{~cm}$. However, there was nearly a three-fold increase in the distance between interacting fish in the absence of the landmark (mean distance between 
fish during face-offs $=63.54 \pm 4.24 \mathrm{~cm}$ ). This increase in the space between fish, which is nearly four times of the total body length of an adult male, was significant (Fig: 6;

Wilcoxon signed-rank test: $\left.\mathrm{W}_{(38)}=0.00, \mathrm{Z}=-5.086, P<0.001\right)$.

Do landmarks affect the precision of territory borders?

The precision of territory boundary was clearly affected by the presence of a landmark. The face-offs that occurred with similar lengths were used for this comparison. In these selected face-offs, the mean length of a face-off that occurred with the presence of a landmark was $33.04 \pm 2.34 \mathrm{~cm}$, while it was $33.56 \pm 2.35 \mathrm{~cm}$ when there was no landmark. Although the mean length of these face-offs was similar in the two treatments, the midpoint of the face-off varied significantly with and without the landmark. With the presence of the landmark, the mean distance to the boundary from midpoints of face-offs was $1.67 \pm 0.52 \mathrm{~cm}$; this value ranged from $0-6.90 \mathrm{~cm}$. When the landmark was absent, the mean distance to the face-off midpoints was $3.43 \pm 2.35 \mathrm{~cm}$, which was a significant different compared to the landmarked treatment (Fig: 7b; Mann-Whitney U test: $U_{(38)}=$ 483.0, $\mathrm{Z}=3.116, P=0.002)$. Also this later distance varied from $0-13.95 \mathrm{~cm}$ from the shared boundary.

Landmarks affected how far a resident fish chased an intruder (Fig: 8; Wilcoxon signed-rank test: $\left.\mathrm{W}_{(38)}=43.0, \mathrm{Z}=-4.132, P<0.001\right)$. With the presence of the landmark, chases were short and ended $0.90 \pm 0.71 \mathrm{~cm}$ before where the shared boundary was located. However, on average, chases ended $15.91 \pm 3.54 \mathrm{~cm}$ past the boundary when there was no landmark. This distance that residents chased the intruders was not 
significantly correlated with the developmental stage of offspring (Spearman rank correlation: $\left.\mathrm{r}_{\mathrm{s}}=0.116, n=64, P=0.396\right)$.

Do landmarks affect where agonistic interactions occur along the boundary?

In order to determine whether landmarks affected the location of interactions, I measured the vertical distance to each face-off from the midpoint of the boundary, which was the site of the plant when it was present. There was a significant difference between the location of interactions that occurred with and without the landmark (Fig: 9b; Wilcoxon signed-rank test: $\left.\mathrm{W}_{(38)}=63.0, \mathrm{Z}=-3.886, P<0.001\right)$. On average, with the presence of the landmark, face-offs occurred $2.25 \pm 0.89 \mathrm{~cm}$ away from the boundary midpoint. Without the plant, the mean distance to a face-off from the boundary midpoint was $6.09 \pm 0.89 \mathrm{~cm}$, which was nearly a threefold increase.

In addition, a total of 187 chases were recorded with the landmark, while $80.2 \%$ of these chases occurred within the $30^{\circ}$ angle from breeding holes. A similar number of total chases $(\mathrm{N}=176)$ were observed without the landmark, but only $42.0 \%$ of chases occurred within the $30^{\circ}$ angle. This change in the number of chases was significantly different (Fig. 10; Chi-squared test: $\chi^{2}=54.37, \mathrm{df}=1, P<0.001$ ). 


\section{DISCUSSION}

The presence of landmarks at territory borders significantly affected the space partitioning interactions and the overall landscape of aggression in H. nicaraguensis. Landmarks influenced the presence of defensive boundary zones, precision of territory border, and the location where interactions occur. The shorter distance between two interacting fish indicated that landmarks reduced the size of boundary zones. Two lines of evidence suggest that the territory boundaries were more precisely defined when such landmarks were available. First, the midpoints of face-offs deviated less and were positioned closer to the shared boundary. Second, landmarks made chases shorter, making it less likely for a fish to intrude into the neighboring territory. In addition, interactions that occurred along the boundary were concentrated near the landmark when they were present.

The reduction in distance between neighbors during face-offs indicates that landmarks must be providing them with more certainty in identifying the exact location of the boundary and therefore may not pose a greater risk to approach it. Face-offs are mildly aggressive acts (LaManna and Eason 2003) that are often used to keep a less threatening intruder away from the resident's territory. In H. nicaraguensis, these faceoffs are usually used against established neighbors (personal observation). Hence, if a resident unintentionally crosses the border when challenging a neighbor, it will significantly increase the risk of escalation and thus the costs associated with that behavior. Hence, when the location of the boundary is uncertain, it may be cost effective to leave a larger area in their territory and use it as a buffer zone. By doing so, the 
territory holder may be benefited as it will lower the risk of escalations that may occur due to accidental intrusions and error in identifying boundary location. Overall, the presence of the significantly larger defensive boundary zones may reduce aggression between neighbors.

However, leaving a large area of the territory as a buffer zone may not always be beneficial for the territory owner, as the size of the territory is vital particularly for the territorial species that defend feeding territories. Such unused areas could become critical when trying to maintain viable breeding populations under unfavorable environmental conditions (Rolstad 1991; Lamberson et al.1994). Hence, those species may have to reasses the costs and benefits associated with the presence of large boundary zones. These findings indicate that providing distinct structures such as landmarks could be useful in maximizing the space use in species that defend feeding territories. However, for $H$. nicaraguensis, abandoning some space in the territory as a buffer zone may not be challenging as they do not feed in their territories (McKaye 1977).

Both the smaller deviation in face-off midpoints and shorter chases support the hypothesis that landmarks are useful in clearly defining territory boundary. The deviation of the face-off midpoints were less with the presence of the landmark, although the mean length of face-offs were similar in both treatments. This indicates that fish do not have a fixed boundary when there are no landmark, even when they face-off from the same distances. A clear territory boundary may alter the risk of intrusion, thereby affecting defense costs. Eason et al. (1999) identified several proximate explanations for how landmarks might be useful in lowering defensive costs. First, individuals in adjacent territories may accidentally intrude into their neighbor's territories because the border 
between them is poorly defined, resulting in an increase in aggressive interactions. Also territory holders may also be less able to identify when a rival has entered their territory. Hence, they will intensify the border patrolling. Even without intruding into neighboring territories, this behavior would tend to increase the frequency of aggressive interactions between neighbors at territorial boundaries.

In addition, landmarks made chases shorter and hence, fish were less likely to intrude into neighboring territories during chases. These shorter chases could be more efficient because a territory owner knows how far it has to chase an intruder. Chases are energetically expensive behaviors (Chellappa and Huntingford 1989) that were more often directed towards unfamiliar intruders than established neighbors (personal observations). Landmarks make it evident for both the resident and the intruder that the costs are dramatically different at and beyond that point. Hence, landmarks may be useful in educating not only the resident but also intruders about territory borders and costs associated with them. On the other hand, these shorter chases could be more cost effective as it may reduce the risk of offspring predation that could occur while a parent is away chasing an intruder. Also, it will prevent chasing intruders in uncertain areas of the territory, which could lead to unintentional escalations with neighbors.

Previous studies have found that landmarks could affect the intensity level (LaManna and Eason 2003) and the frequency of agonistic interactions (Smith 2011). However, little is known about whether landmarks would affect the location where interactions occur. Both face-offs and chases tended to occur closer to landmarks when such landmarks were available. For example, the number of chases that occurred under two treatments did not vary significantly, but when the landmark was absent, only $40.0 \%$ 
chases occurred near the midpoint of the boundary while it doubled with the presence of the landmark. This observation suggests that $H$. nicaraguensis are likely to alter where they interact with neighbors depending on the availability of visual landmarks.

Landmarks indicate the precise location of the boundary; thus coordinating their behavior to meet and interact with neighbors at that particular location could potentially lower the risk of error made during the assessment of territory borders. However, it is arguable, that the increase in interactions that occurred at the plant could be a result of accidental meetings of fish that came to investigate the novel object or the potential food source, given that these are herbivores. Nonetheless, the control experiment revealed that the plant did not affect the number of visits residents paid to the particular region. Hence, it is clear that the fish met at the landmark intentionally to settle disputes with neighbors.

By placing the landmark at the midpoint of the shared boundary, I increased the possibility that fish would interact there even though that site may not necessarily have been in their best interest. Fish centered most of their interactions near the landmark, implying that fish mutually agreed to adopt it to demarcate the territory boundary. Mesterton-Gibbons \& Adams (2003) identified the conditions under which acceptance of landmarks as conventions are likely to occur. These conditions include a situation where a landmark divides a territory fairly, when the marginal value of increased territory size is low, when both contestants are uncertain as to their relative fighting abilities, and when the costs of fighting are high. Most of these conditions were observed in H. nicaraguensis territoriality too. Mutual adoption of the landmark would have been an easier decision for H. nicaraguensis as I placed the landmark at the midpoint of the already existing boundary, which did not result in a change in territory size for either neighbor. In 
addition, the increase in territory size in unlikely to yield a higher benefit since $H$. nicaraguensis defend non-feeding territories. Although adults are capable of aggressive fights, they rarely engaged in them during the study period (personal observations). One explanation for this behavior could be that the costs of fights are higher partly due to the greater risk of fry predation at Xiloá. Although this information may support the convention hypothesis, more robust experiments should be conducted to substantiate the convention hypothesis.

In summary, findings of this study identify the effects of landmarks on the space use and the agonistic landscape of territorial neighbors. Landmarks were useful in precisely defining territory borders, making intruder chases shorter, and relocating agonistic interactions. These effects could directly impact the overall defensive cost of a territory. This is the first field study to experimentally demonstrate that landmarks are useful in clearly defining territory borders. In addition, these results have important implications for wildlife managers and captive breeders as they suggest that by providing appropriate habitat features such as landmarks, we could maximize the use of space by territorial species. Future studies might attempt to quantify the buffer effect by focusing on the percent of intruders chased from different parts of the territory. Also, it will be interesting to investigate whether territory-demarcating landmarks are selected and used unilaterally or whether their function is derived by a mutual convention between neighbors. 


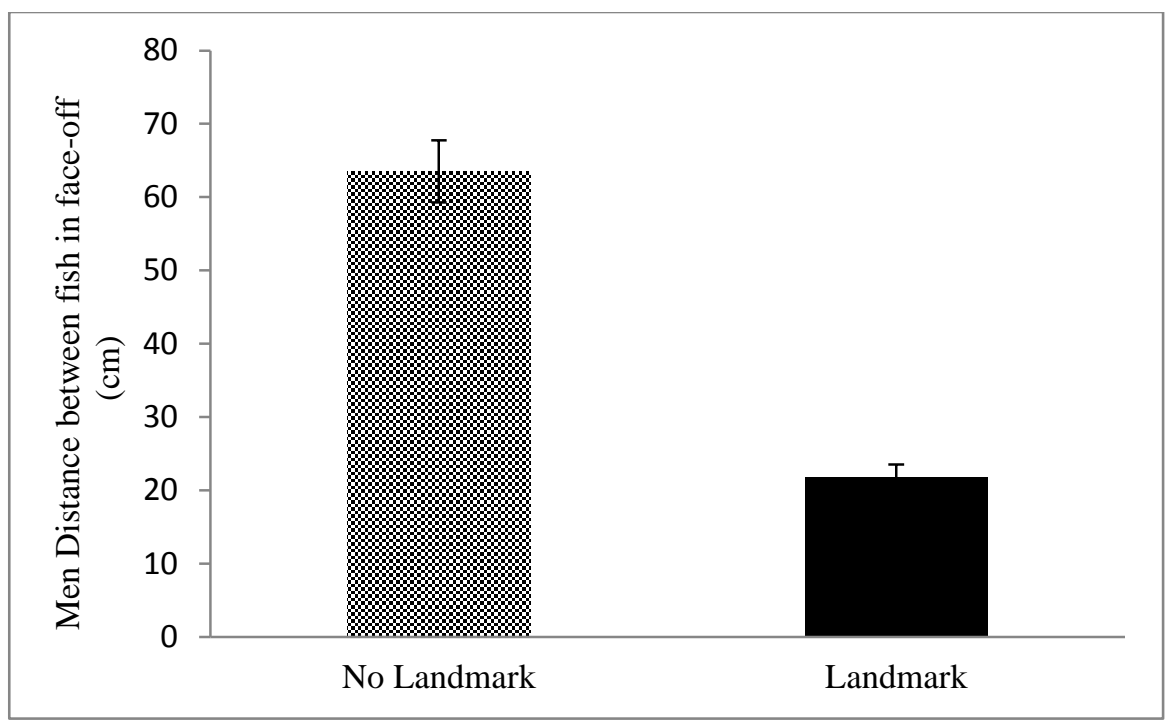

Figure 6: The mean distance between fish during face-offs.

Fish left a larger area between them when interacting with one another in the absence of a landmark (Wilcoxon signed-rank test: $\mathrm{W}_{(38)}=0.00, \mathrm{Z}=-5.086, \mathrm{~N}=38, P<0.001$ ). Error bars indicate the standard error. 


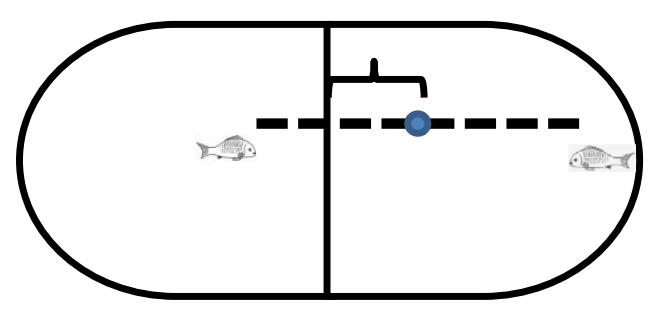

Figure 7a: The schematic diagram: Measuring the distance to face-off midpoint from the boundary.

The solid line indicates territory boundaries. The dotted line represents the length of the face-off. The circle in the middle of the dotted line is the midpoint of the face-off. The distance to face-off midpoint from the shared boundary is represented by the curly bracket.

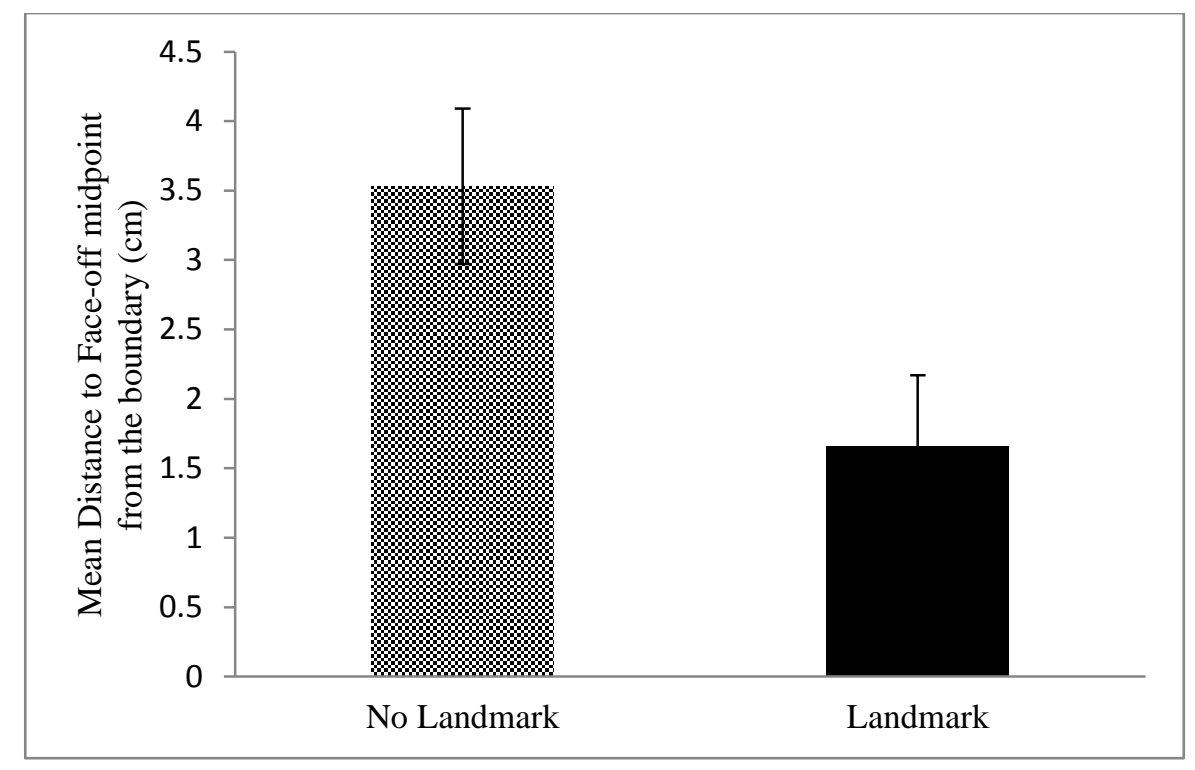

Figure 7b: Mean distance to face-off midpoint from the boundary.

The midpoints of face-offs were closer to the boundary with the presence of a landmark (Mann-Whitney $\mathrm{U}$ test: $\mathrm{U}_{(38)}=483.0, \mathrm{Z}=3.116, P=0.002$ ). Error bars indicate the standard error. 


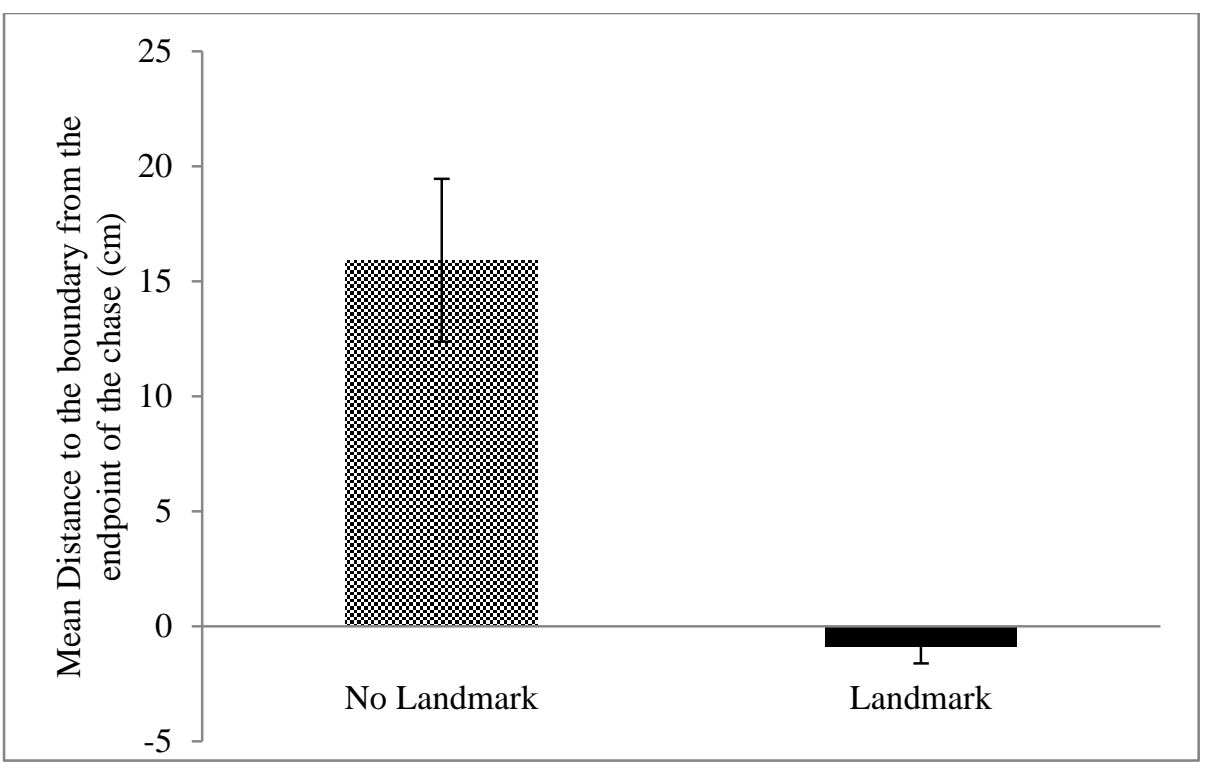

Figure 8: Mean distance to the boundary from the endpoint of the chase.

Chases were shorter with the presence of landmarks (Wilcoxon signed-rank test: $\mathrm{W}_{(38)}=$ 43.0, $\mathrm{Z}=-4.132, \mathrm{~N}=38, P<0.001)$. Error bars indicate the standard error. 


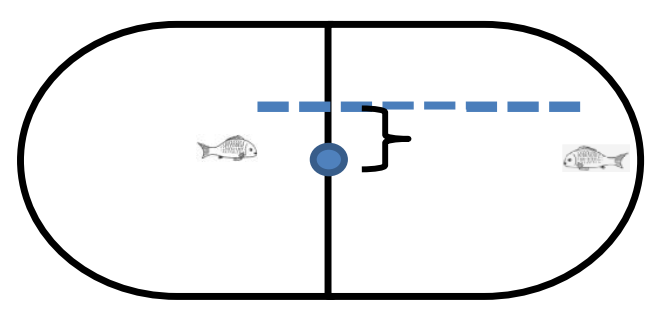

Figure 9a: The schematic diagram: Measuring the distance from the boundary midpoint to face-off.

The solid line indicates territory boundaries. The dotted line represents the length of the face-off. The circle in the middle of the shared boundary is the midpoint of the boundary. The distance from the boundary midpoint to face-off is represented by the curly bracket.

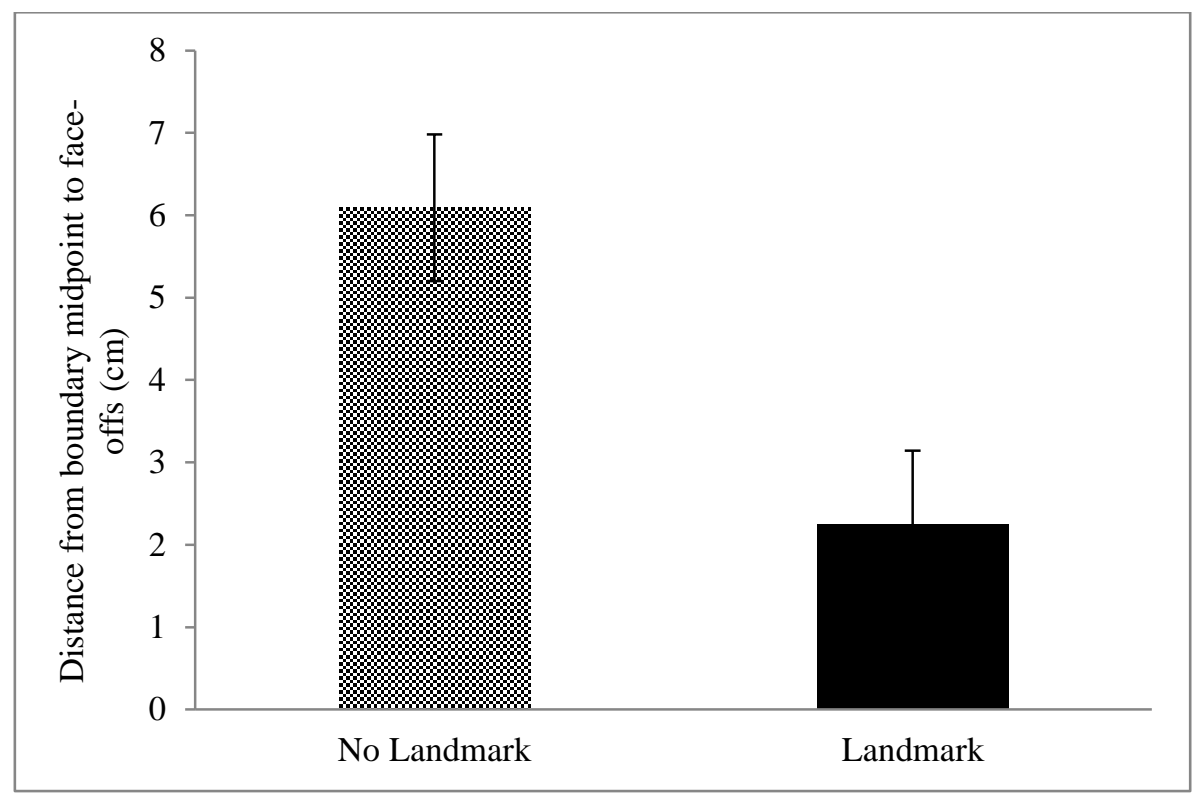

Figure 9b: Vertical distance from the boundary midpoint to face-offs.

Interactions tended to occur closer to landmarks when such landmarks were available (Wilcoxon signed-rank test: $\mathrm{W}_{(38)}=63.0, \mathrm{Z}=-3.886, \mathrm{~N}=38, P<0.001$ ). Error bars indicate the standard error. 


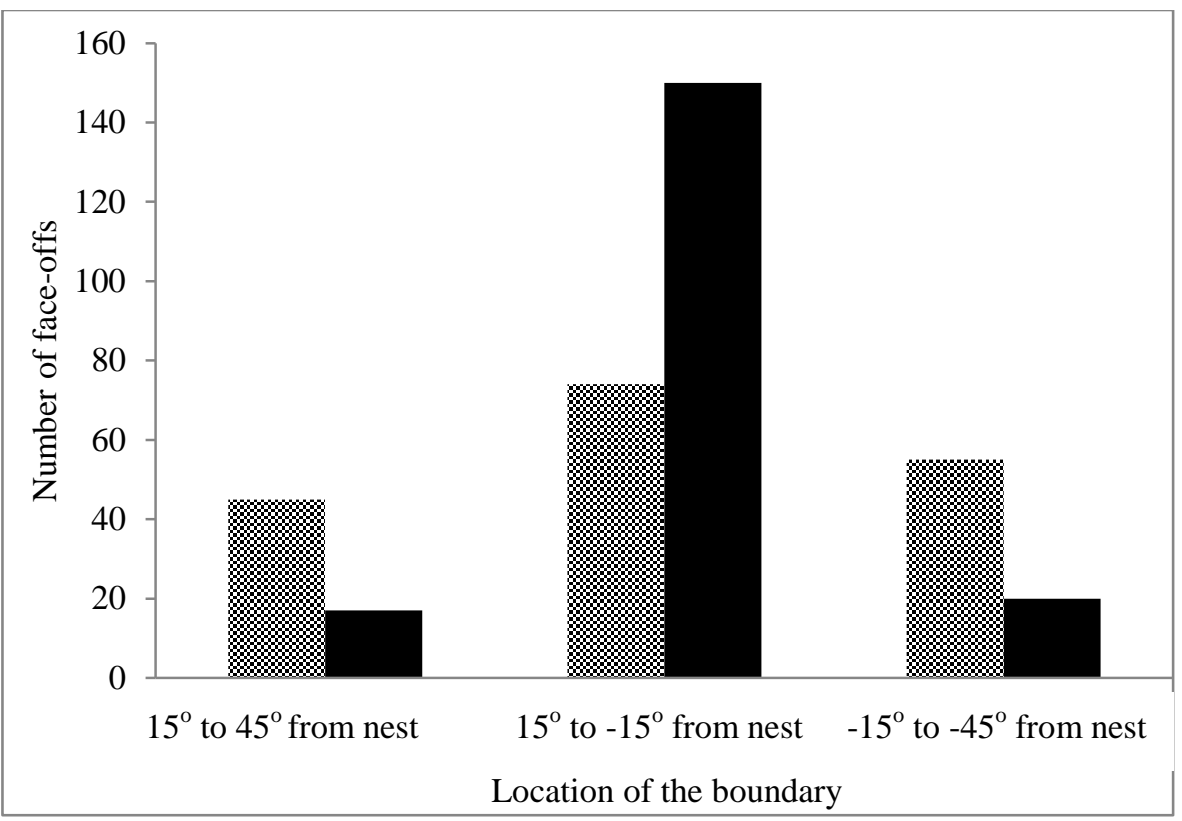

Figure 10: The number of interactions that occurred at different locations of the boundary.

More interactions occurred near the midpoint of the boundary when it had a landmark (Chi-squared test: $\left.\chi^{2}=54.37, \mathrm{df}=1, P<0.001\right)$. 


\section{CHAPTER III}

\section{MANIPULATING TERRITORIES VIA LANDMARKS}

The territory boundary, within which the resident is intolerant of other individuals, spatially defines the territory (Heap et al. 2012). Despite its significance, little is known about how the social interactions between individuals may affect the location of the boundary (Maynard Smith 1982; Stamps 1994; Adams 2001; Pereira et al. 2003), leading to a modification in territory properties. Intraspecific variation in territory size and shape can affect individual fitness and the social interactions of a territorial species (Hixon 1980; Scheoner 1983; Both and Visser 2000; Walkin et al. 2006). In addition, such disparities among territories can have strong influences on the structure and dynamics of territorial populations (Adams 2001).

Most theoretical and empirical work has focused on the optimization of territory size, identifying resource distribution and defensive costs as primary determinants of optimal size (Schoener 1983). In contrast, there have been few studies explicitly investigating territory shape (but see Getty 1981; Ford 1983; Eason 1992; Eason and Stamps 1992). Theoretical work on territory shape predicts that territories should be round, and in nature, many territories do approximate a circle (Andersson 1978; Dill 1978; Hixon 1980; Adams 2001). The idea that a round territory is optimal is based on the assumptions that defense costs are minimized in a round territory compared to an 
elongated or irregularly shaped territory of the same size, and that resources are distributed uniformly within the territory (Eason 1992).

However, in nature these conditions are not always met, and some studies suggest that landmarks and uneven topography can affect territory shape and size by altering demands of defensibility. For example, presence of landmarks has been shown to reduce the size of territories in fish (Baylis 1974; Kodric -Brown 1978; LaManna and Eason 2003). In addition, Grant (1968) suggested that the shape of the pectoral sand-piper (Calidris melatonos) territories is affected by the existence of a landmarked boundary. The topography of the habitat affected the shape of red-capped cardinal, Paroaria gularis, territories, as that particular shape made the identification and eviction of intruders easier (Eason 1992).

In this field study, I examined the effects of landmarks on territory size, shape and the location of territorial boundaries. Exploring the relationship between landmarks and boundaries can provide important insights to understand the decisions related to boundary formation and maintenance and the division of space between individuals (St-Louis et al. 2004; Smith 2011). Although we have little understanding of how flexible territorial boundaries can be, responsiveness to changes in the landscape could benefit territorial residents by reducing their defensive costs. Such responsiveness would also enable researchers to manipulate territories to test theoretical predictions about territoriality.

This study consisted of two primary parts:

1. A field survey to determine whether the presence of a landmarked boundary affects the size and shape of convict cichlid territories under natural conditions. 
2. An experimental manipulation of convict territories to determine whether these cichlids would change the size, shape, and boundaries of their territories in response to a landmark.

In this study, I observed the territorial behavior of Amatitlania siquia, a species in the convict cichlid group. It is a sequentially monogamous, substrate-brooding cichlid that provides bi-parental care for offspring (Alonzo et al. 2001). A pair of convicts spawns in a breeding hole that is later used for keeping the offspring safe overnight (Wisenden 1994b; 1995; Alonzo et al. 2001). I selected A. siquia for this study for several reasons. It is the third most numerous cichlid at Lake Xiloá (McKaye 1977) and the most common species found in waters less than $15 \mathrm{~m}$ deep (personal observations). Since competition for breeding sites among cichlids in Lake Xiloá is intense (McKaye 1977), they tend to occupy any suitable substrate for spawning. This feature increased the likelihood of success for the experimental manipulation, in which empty beer cans were provided as artificial breeding sites. In addition, females are smaller than males and have ventral color markings that are absent in males (McKaye 1986; Lehtonen et al. 2011). This sexual dimorphism and the unique individual stripe patterns (personal observations) facilitate accurate identification of individuals during observations. Moreover, both male and female aggressively defend territories from conspecific and heterospecific intruders (Alonzo et al. 2001), and successful territory defense is a central determinant of their reproductive output (Keenleyside 1991). 


\section{METHODS}

Study Site

The study was conducted in Lake Xiloá, a neotropical crater lake in Western Nicaragua using SCUBA. Both the preliminary survey and experimental manipulations were conducted off the lake's eastern shore at depths from $8-15 \mathrm{~m}$ in an area approximately $85 \mathrm{~m}$ by $30 \mathrm{~m}$. This site is characterized by a moderate slope, and the substrate is comprised of silt and sand, Chara sp. beds and scattered stone outcroppings (Alonzo et al. 2001). This particular region of the lake was selected for the study because the convict breeding pairs occur at their highest density at this depth due to substrate availability, higher level of primary production and low numbers of larger cichlid fish species (McKaye 1977; Alonzo et al. 2001).

\section{Reconnaissance Survey}

The survey was conducted in March 2011 for six consecutive days. Observations were made from 0930 to 1130 and 1330 to 1530 hours daily. I identified breeding territories by swimming parallel to the shore and looking for a male and a female that were within close proximity (Snesker et al. 2011). Once I located a breeding pair, I began data collection after five minutes of acclimation period. I observed the behavior of fish from one to two meters away for 10 minute bouts. I recorded chase locations of intruders. Location of a chase was considered to be the position of the intruder when the resident initiated the chase (Breau and Grant 2002). I then used these locations to outline the 
territory boundary using the minimum convex polygon method (Mohr 1947). At the end of the ten-minute observation period, I collected the following data from each territory.

1. Territory length: Greatest linear distance between territory boundaries

2. Territory width: Greatest distance between boundaries perpendicular to the length

3. Total lengths of the breeding pair: Approximated the total lengths of a pair by close observations and calibrated the approximations by placing a model of the fish with known standard lengths next to the breeding pair. Also, I set out rulers to measure the distance between objects by which fish were still.

4. Stage of fry: Offspring were grouped into four categories as egg, wrigglers, fry and juveniles. Wrigglers are newly hatched offspring with the yolk sac and poorly developed fins (Wisenden and Dye 2009). The next free swimming stage is called fry. They are four to six weeks of age. After week six, fry metamorphosed into juveniles. They have the adult stripe pattern and are ready for a life independent of their parents (Wisenden et al.2008).

5. Topography of the territory: Territories were divided into three habitat types: sandy, weed, and rocky habitat. I categorized habitats according to the prominent features of the substrate. Approximately, $80 \%$ of the weedy habitat was dominated by Chara bed. Similarly, rock outcroppings covered nearly $80 \%$ 
of the surface of the rocky habitat. Rocks and weed were sparsely distributed in sandy habitat and $80 \%$ of the substrate was dominated by sand and silt.

During the survey, I observed a total of 104 breeding pairs of A. siquia. I marked each territory observed with a survey flag to prevent resampling.

\section{Experimental Manipulation}

Experimental manipulations were conducted in December 2012 using SCUBA. Study was confined to the sandy habitat of the lake's eastern shore and data was collected for eight consecutive days. I provided empty beer cans $(12 \mathrm{~cm}$ in height and $6 \mathrm{~cm}$ in diameter) as artificial breeding sites and allowed seven days for breeding pairs to nest. The cans were placed at least two meters apart in order to make the territories noncontiguous. As landmarks, I used open-branched plastic plants that were $6 \mathrm{~cm}$ wide and similar in form to the naturally occurring Chara sp. in the lake and placed them $6 \mathrm{~cm}$ from the can's opening. Fish were readily visible through the plants, and residents swam through the plants, which thus did not appear to affect their movement pattern. I compared territories' size, shape, and boundary location in trials without landmarks to trials with a point landmark, one plant $(\mathrm{N}=24)$ or a linear landmark, four immediately adjacent plants $(\mathrm{N}=24)$. I observed each pair's behavior for 10 minutes with and without landmarks, alternating which trial occurred first and performing the second trial 24 hours after the first. All the observations were made from a distance of one to two meters from fish, after allowing them up to five minutes to acclimate. 
The same techniques used in the preliminary survey were used to collect the following data in the experimental manipulation.

1. Chases' locations used to map territories

2. Length and width of territory

3. Total lengths of breeding pair

4. Stage of fry

In addition, I measured the distance from the nest to the boundary in two treatments. Before trials, I determined where I would place plants. I then measured distance from nest to the boundary in that direction in all trials, whether or not plants were present.

\section{Data Analyses}

As a measure of territory shape, I used the ratio between territory length and width. In order to compare territory sizes, I analyzed a scaled digital image of each territory using ImageJ software.

In the reconnaissance survey, to eliminate the effect of varying degree of landmark cover, I first determined the perimeter of each territory and then calculated the percentage of boundary at the landmark. To investigate whether landmarked boundaries affected the size of territories, first, I linearized data using $\log (\mathrm{x}+1)$ transformation and then performed a Spearman rank correlation. To examine whether landmarked boundaries affected the shape of territories, I used another Spearman rank correlation 
between territory shape, i.e. length to width ratio and the percentage of boundary at landmark.

In the experimental manipulation, I compared territory size, shape and boundary location in trials without landmarks to trials with a point landmark or a linear landmark. First, in order to determine whether the order of placing the landmark had a significant effect on the response, I performed Mann-Whitney U tests. Then I combined data from point landmark first and point landmark second treatments together. Similarly, I combined data from linear landmark first and linear landmark second treatments together too. I then used Wilcoxon signed-rank tests to analyze territory size, shape and the distances from the nest to the boundary with and without landmarks.

All data analysis was carried out on Minitab 16 Statistical Software (2010), and means are reported $\pm \mathrm{SE}$. 


\section{RESULTS}

\section{Reconnaissance Survey:}

Out of 104 breeding pairs observed during the survey, $39.4 \%$ and $33.6 \%$ of territories were found in weedy and sandy habitats, respectively. Only $27.0 \%$ of the territories observed were found in the rocky habitat. On average, male convicts were 4.86 $\pm 0.07 \mathrm{~cm}$ in total length, while females were $3.28 \pm 0.06 \mathrm{~cm}$ in total length. Out of all the breeding pairs observed, $11.21 \%$ of them did not yet have eggs, $37.38 \%$ had eggs or wrigglers in their breeding sites, $36.45 \%$ had free swimming fry, while the remaining $14.95 \%$ had juveniles.

Do landmarked boundaries affect territory size and shape?

Two significant differences in territory properties were observed between territories with landmarked boundaries and territories without landmarked boundaries. First, the territory size decreased as the percentage of boundary at landmarked increased (Fig.11; Spearman rank correlation; $\mathrm{R}^{2}=-0.815, n=104, P<0.001$ ).

Second, a significant difference in territory shape was also observed as the percentage of boundary at landmarked increased (Fig.12; Spearman rank correlation; $\mathrm{R}^{2}$ $=0.796, n=104, P<0.001)$. Territories were nearly circular in shape when less than $10 \%$ of the boundary was bordered by a landmark (length-to-width ratio: $1.05 \pm 0.02$ ), with mean overall lengths of $64.28 \pm 4.81 \mathrm{~cm}$ and widths of $62.18 \pm 4.97 \mathrm{~cm}$, for an overall mean diameter of $63.23 \pm 3.39 \mathrm{~cm}$. Territory shape gradually became elongated as the percentage of boundary at landmark increased. However, this pattern tended to be 
somewhat irregular and territories tended to shift between circular and elongated shapes when approximately half of the territory was bordered with a landmark. Beyond $40 \%$ landmark cover, there were two distinct groups of territories. The territories that were more elongated in shape were always margined by longer linear landmark, such as a boulder or a line of weeds. On the other hand, the territories that were more circular in shape were margined by landmarks that resembled arc-shaped arrangements.

\section{Experimental Manipulation:}

Males observed during the experimental manipulation were $4.78 \pm 0.08 \mathrm{~cm}$ in total length on average, while females were $3.68 \pm 0.05 \mathrm{~cm}$ in total length. Out of the 48 breeding pairs observed, $52.08 \%$ of them had eggs, $27.08 \%$ had wrigglers in their breeding sites and $20.83 \%$ had free swimming fry. On average, $29.71 \pm 4.08$ chase locations were recorded per trial in the point landmark treatment and were used to outline territory borders. In the linear landmark treatment, an average of $24.19 \pm 3.89$ chase locations were recorded per trial, which I used to outline the territory border.

Whether focal pairs were observed first with or without landmarks did not significantly affect territory size nor shape or the distance from the nest to the boundary in either the point landmark or linear landmark treatment (see Appendix I).

\section{Do landmarks affect territory size?}

Landmarks affected territory size, shape, and the distance from the nest to the boundary in both the point landmark treatment (see fig. 13a) and the linear landmark treatment (see fig. 13b). Presence of a landmark significantly reduced territory size in 
both treatments. In the point landmark treatment, the mean territory size was $0.29 \pm 0.03$ $\mathrm{m}^{2}$ when there was no landmark but it was $0.24 \pm 0.03 \mathrm{~m}^{2}$ when the landmark was present (Wilcoxon signed-rank test: $\mathrm{Z}=-2.403, n=24, P=0.016$ ). Similarly, in the linear landmark treatment, territory size averaged $0.22 \pm 0.02 \mathrm{~m}^{2}$ without landmarks but it was $0.16 \pm 0.01 \mathrm{~m}^{2}$ with the landmark (Wilcoxon signed-rank test: $\mathrm{Z}=-2.714, n=24, P=$ $0.007)$.

\section{Do landmarks affect territory shape?}

In the point landmark treatment, territory shape was always nearly circular, with mean overall lengths of $64.98 \pm 2.44 \mathrm{~cm}$ and widths of $57.44 \pm 2.49 \mathrm{~cm}$, for an overall mean diameter of $61.21 \pm 1.78 \mathrm{~cm}$. Shape did not change across trials (Fig. 14a; mean length-to-width ratio without landmarks $=1.14 \pm 0.02$, with the point landmark $=1.18 \pm$

0.03; Wilcoxon signed-rank test: $\left.\mathrm{W}_{(24)}=111.5, \mathrm{Z}=-0.844, n=24, P=0.401\right)$. However, in contrast to the point landmark treatment, a significant change in shape occurred in the linear landmark treatment (see Fig. 13b). With the linear landmark, territories were more elongated (length-to-width ratio: $1.86 \pm 0.04$ ) than when landmarks were absent (Fig. 14b; length-to-width ratio: $1.14 \pm 0.02$; Wilcoxon signed-rank test: $\mathrm{W}_{(24)}=0.0, \mathrm{Z}=$ 4.286, $n=24, P<0.001)$.

\section{Do landmarks affect the distance from the nest to the boundary?}

Boundary location changed across trials in both treatments. In the point landmark treatment, when there was no landmark, the nest was near the center of the territory (Fig. 15a). Mean distance between nest and boundary was $23.28 \pm 1.54 \mathrm{~cm}$, which was $48.21 \pm$ 
$2.06 \%$ of the territory diameter. With the point landmark, fish set their territory boundary closer to the landmark; nests were a mean distance of $8.40 \pm 1.45 \mathrm{~cm}$ from the boundary, equal to $25.01 \pm 1.93 \%$ of territory diameter (Wilcoxon signed-rank test: $\mathrm{W}_{(24)}=1.0, \mathrm{Z}$ $=-4.229, P<0.001)$. A similar shift in territory boundary occurred in trials in the linear landmark treatment. With no landmark, mean distance between nest and boundary averaged $20.54 \pm 1.14 \mathrm{~cm}$, or $51.11 \pm 1.74 \%$ of the territory diameter; however, with the presence of the linear landmark, the boundary was only $3.71 \pm 0.38 \mathrm{~cm}$ from the nest, or $26.52 \pm 2.27 \%$ of territory width (Fig. 15b; Wilcoxon signed-rank test: $\mathrm{W}_{(24)}=0.0, \mathrm{Z}=$ 4.286, $P<0.001)$. 


\section{DISCUSSION}

Results from the preliminary survey suggested that landmarked boundaries tend to affect the size and shape of A.siquia territories. Territories found with a landmarked boundary (margined with weed or rocks) tended to be more elongated in shape and smaller in size. Sandy habitat lacked distinct structures that could potentially act as landmarks, and territories on sand were nearly circular in shape and larger in size. However, the landmarked territories observed during the survey lacked uniformity because they were distributed across different habitats and were supported by differently sized landmarks. For example, some territories in the rocky habitat were margined by a several small rocks while others were lined with boulders. Similarly, in the weedy habitat, there were territories bordered with a dense line of weed while others were bordered with few plants. Landmarks also alternate visibility. Visibility would be lower in weeds than on open sand, and lower visibility might have the same result as the presence of landmarks, i.e. a smaller territory (Kalleberg 1958; Eason and Stamps 1992; Imre et al. 2002). Moreover, the variation in food availability at different habitats would have confounding effects on territory size. Territories in weeds are likely to be higher in food availability compared to territories found in rocky and sandy habitats, and theoretical analyses predict that higher food availability would result in smaller territories too (Eberhard and Ewald 1994).

In order to eliminate the effects of this habitat heterogeneity, I confined the experimental manipulation to the sandy habitat and tested each breeding pair with and without landmarks. In addition, I investigated how the arrangement of a landmark 
affected the territory properties by providing one plant as a point landmark and four adjacent plants as a linear landmark.

In the experimental manipulation, Amatitlania pairs rapidly adjusted their territorial boundaries in response to the presence of a landmark. Similar to the observations of the preliminary survey, landmarks affected the territory size and shape in experimental manipulations. In addition, the location of the boundary in relation to nests was also altered as a response to the presence of the landmark. Territories without landmarks were nearly circular, in accordance with the generally accepted idea of the optimal territory shape (Andersson 1978; Dill 1978; Hixon 1980; Adams 2001) with the nest being approximately in the center. A centrally located nest is likely to facilitate brood defense against predators. When either one or four plants were present, fish set their territorial boundary near that landmark and thus the nest. In addition, similar to the observations of the preliminary survey, territories were significantly smaller with the presence of landmarks. With the point landmark, territory shape did not change, but when the linear landmark was present the territories were significantly more elongated.

With the presence of landmarks, convicts moved their territory boundary within a 24-hour period, and they moved it a fairly large distance. For example in the point landmark treatment, the boundary shifted $14.9 \mathrm{~cm}$ between trials, a distance that was $23.8 \%$ of the mean territory diameter with a landmark present. This remarkable shift in territory boundary demonstrates that fish preferentially situated their boundary at visual landmarks when such landmarks were available. The willingness of fish to move the boundary closer to the nest suggests that landmarked boundaries provide benefits, given that having the boundary near the nest may increase the risk of predation of fry. In other 
species, setting boundaries at landmarks is strongly linked with a reduction in defensive costs (Eason et al. 1999; LaManna and Eason 2003; Heap et al. 2012). Clearly defined boundaries can allow residents to easily determine when another individual has intruded and can reduce time spent defending against neighbors (Eason et al.1999). Although conspicuous landmarks could lower the defensive costs, adjusting territory boundaries is possible only when territories are not contiguous (Eberhard and Ewald 1994; Sherman and Eason 1998), or when individuals are not highly territorial (Mares et al. 1982; Sullivan and Klenner 1992). Territories observed in this study were not contiguous and were found far apart allowing fish to rapidly adjust the boundaries to obtain the benefits of visual landmarks.

The reduction in territory size observed with the presence of landmarks indicates that it is beneficial to defend a smaller territory with well-defined boundaries compared to a larger territory with undefined borders. This decline in territory size was mainly driven by the relocation of the border closer to the landmark by giving up an area that was not clearly defined. If fish needed to defend a territory with a fixed size, then they would still try to maintain it by extending other borders, but such alternation was not observed in this study. There could be two possible explanations for this reduction in territory size. One is that it could be too costly to chase intruders that are farther away as they are less threating, in order to maintain a set territory size. On the other hand, if residents extend their territory boundary, chasing intruders farther away, they may risk the defense of fry as it will take longer for residents to get back to the nest to protect offspring from predators after a chase. Similar reduction in territory size in the presence of landmarks has been reported in previous laboratory experiments (LaManna and Eason 
2003; Van den Assem 1967) as well as on Kodric-Brown's field work on pupfish Cyprinodon sp. (1978).

Despite the presence of a point landmark has the potential to clearly define territory boarders, it may not be substantial to alter the optimal round shape of the territory. Territories observed in the survey were often bordered with a line of weed or rocks and were elongated in shape, similar to the territory shape seen in the experimental manipulation with the linear landmark. One possibility for the alteration of the territory shape is that the fish may mimic the longer shape of the landmark making the territory shape longer too. A similar alteration of territory shape was reported in pectoral sandpiper (Calidris melatonos) territories that were found with and without landmarked boundaries (Grant 1968). It is arguable, that the four plants provided to breeding pairs as a linear landmark may act like a visual barrier leading to the changes observed in territory shape. However, fish were readily visible through the plants, and they effortlessly swam through these open-branched plants, frequently chasing intruders on the opposite side of the plants. These behaviors indicated that the landmarks did not act like an obstruction although they could add structural complexity.

In summary, findings of this study suggest that a simple landmark could be easily used to alter the optimal shape of a territory. Landmarks affected territory size, shape and the location of the boundary. The willingness of fish to allow these modifications in territory properties indicates the benefits of having a landmark at the boundary. Visual landmarks are capable of lowering defensive costs by clearly defining territory boundaries. This is the first field study to suggest that landmarks can affect both the size and the shape of territories by altering where territory boundaries are located. Future 
studies should address the costs and benefits associated with landmarks over extended periods of time in order to fully understand their effects on territory boundaries. 


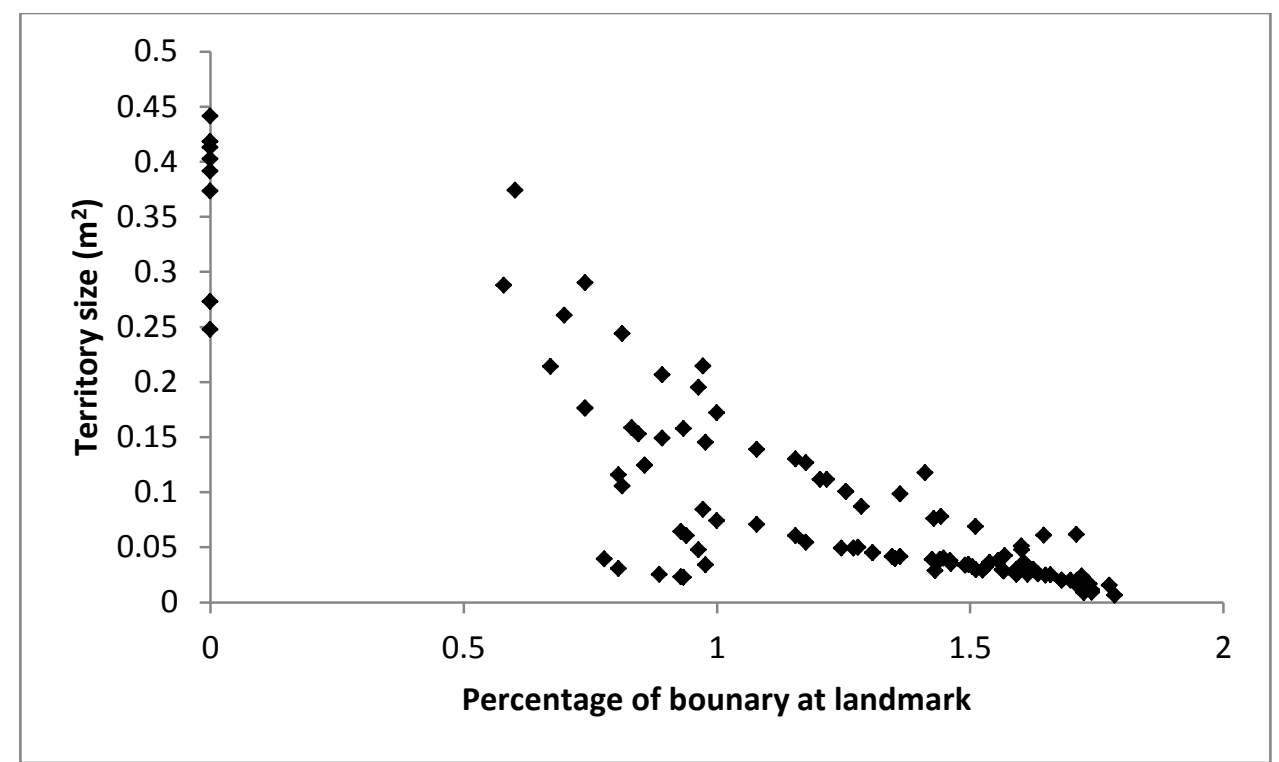

Figure 11: The size of territories observed in the survey with varying degree of landmark cover.

The territory size decreased as the percentage of boundary at the landmark increased. (Spearman rank correlation; $\mathrm{r}_{\mathrm{s}}=-0.815, n=104, P<0.001$ ). Data were linearized using $\log (\mathrm{x}+1)$ transformation. 


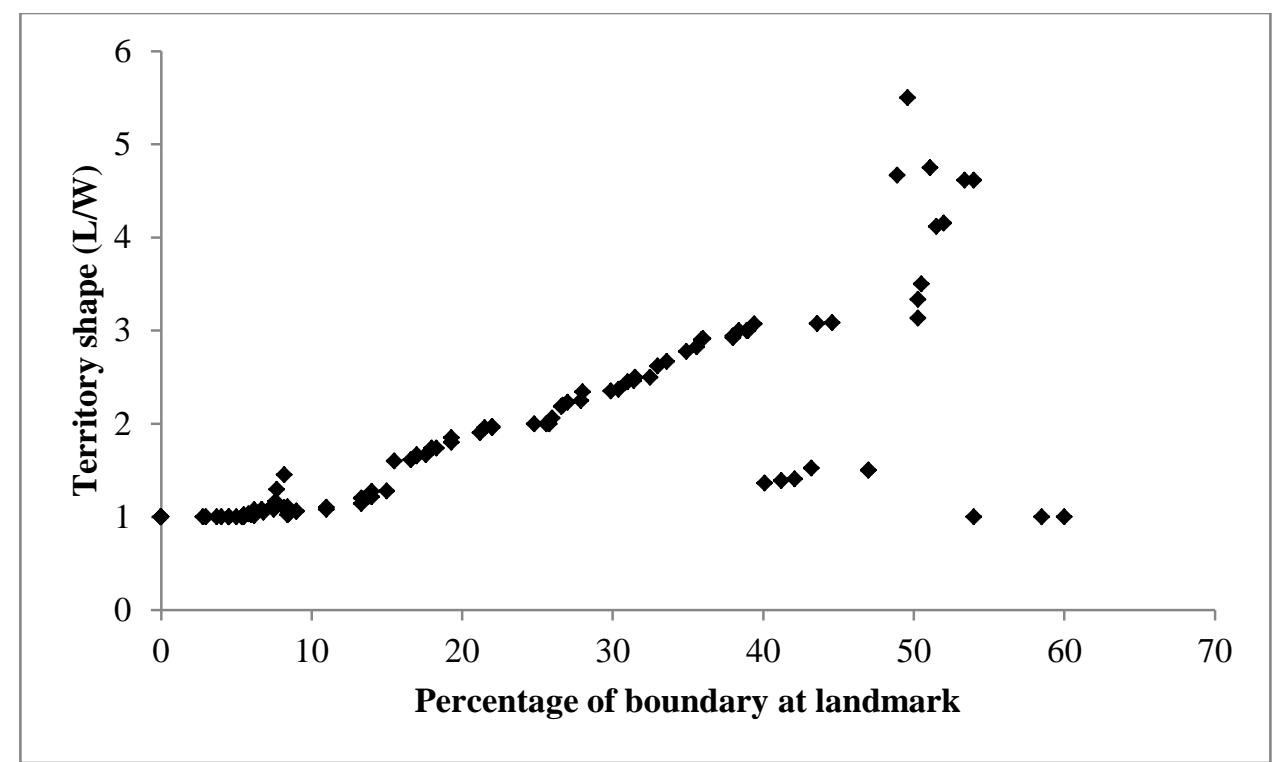

Figure 12: The shape of territories observed in the survey with varying degree of landmark cover.

The shape of territories changed from circular to elongated as the percentage of boundary at the landmark increased (Spearman rank correlation; $\mathrm{r}_{\mathrm{s}}=0.796, n=104, P<0.001$ ). 

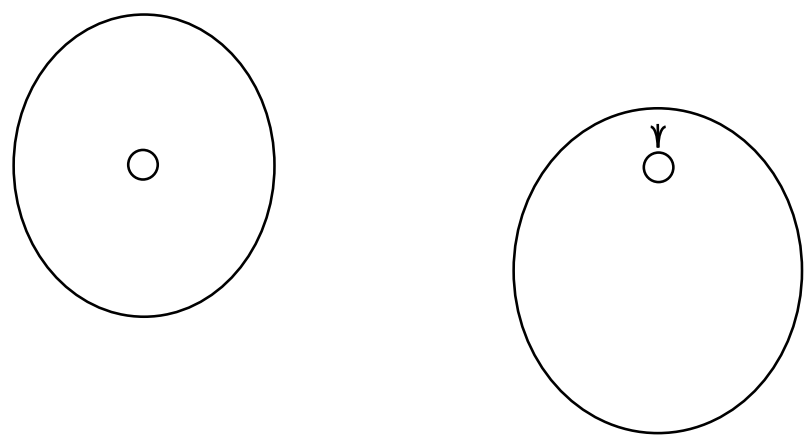

Figure 13a: Scaled diagram of territories with no landmark and a point landmark. Territory shape was always nearly circular, but when a point landmark was present, fish moved their territory boundary close to the landmark and thus the nest.
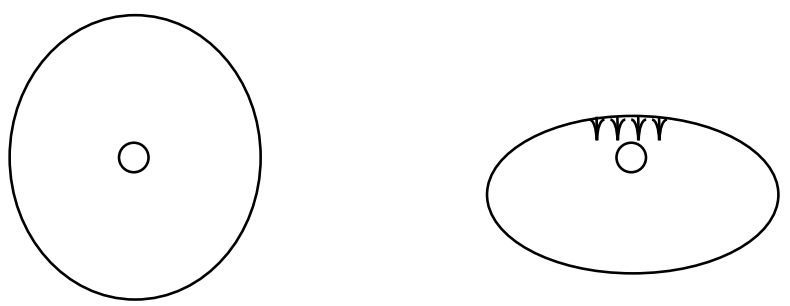

Figure 13b: Scaled diagram of territories without and with a linear landmark.

With the landmark, territories were more elongated than when it was absent. When the linear landmark was present, fish moved the territory boundary closer to the landmark and thus the nest. 


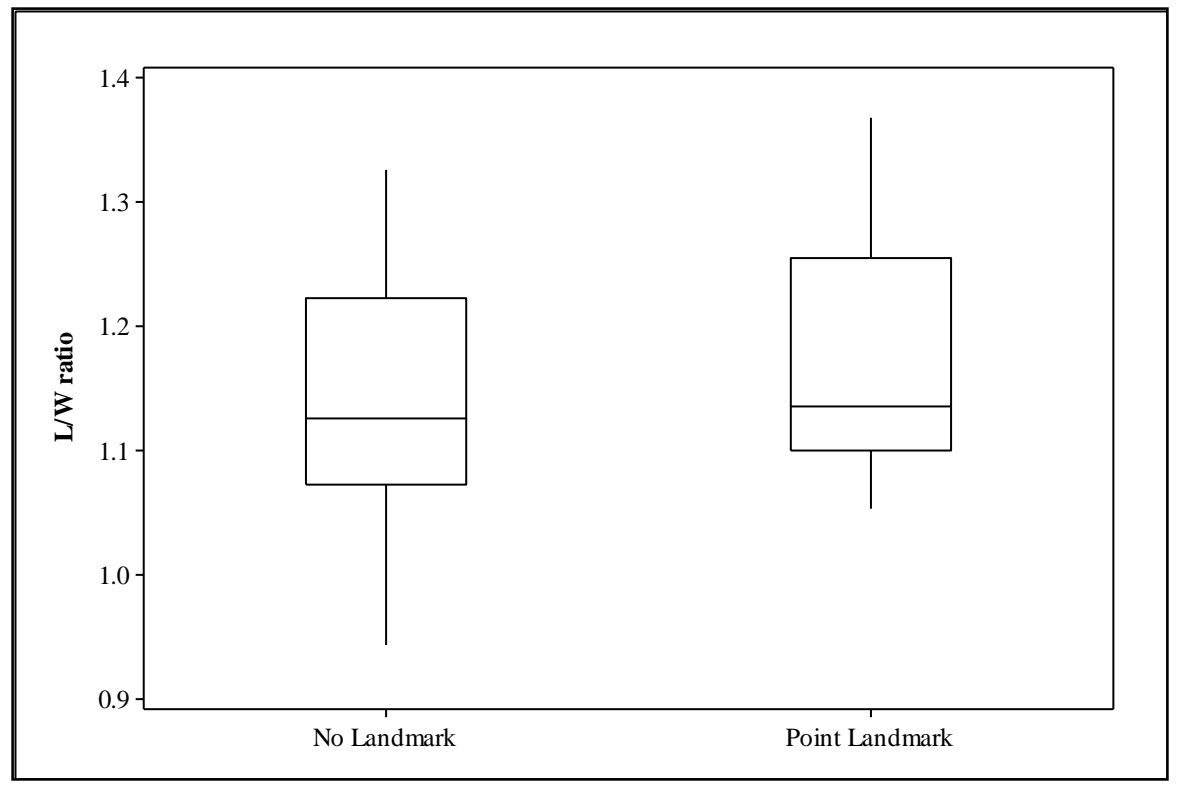

Figure 14a: Territory shape with no landmark and with the point landmark.

Territory shape was always nearly circular and did not change across trials ( $\mathrm{W}_{(24)}=$ 111.5, $\mathrm{Z}=-0.844, n=24, P=0.401)$. 


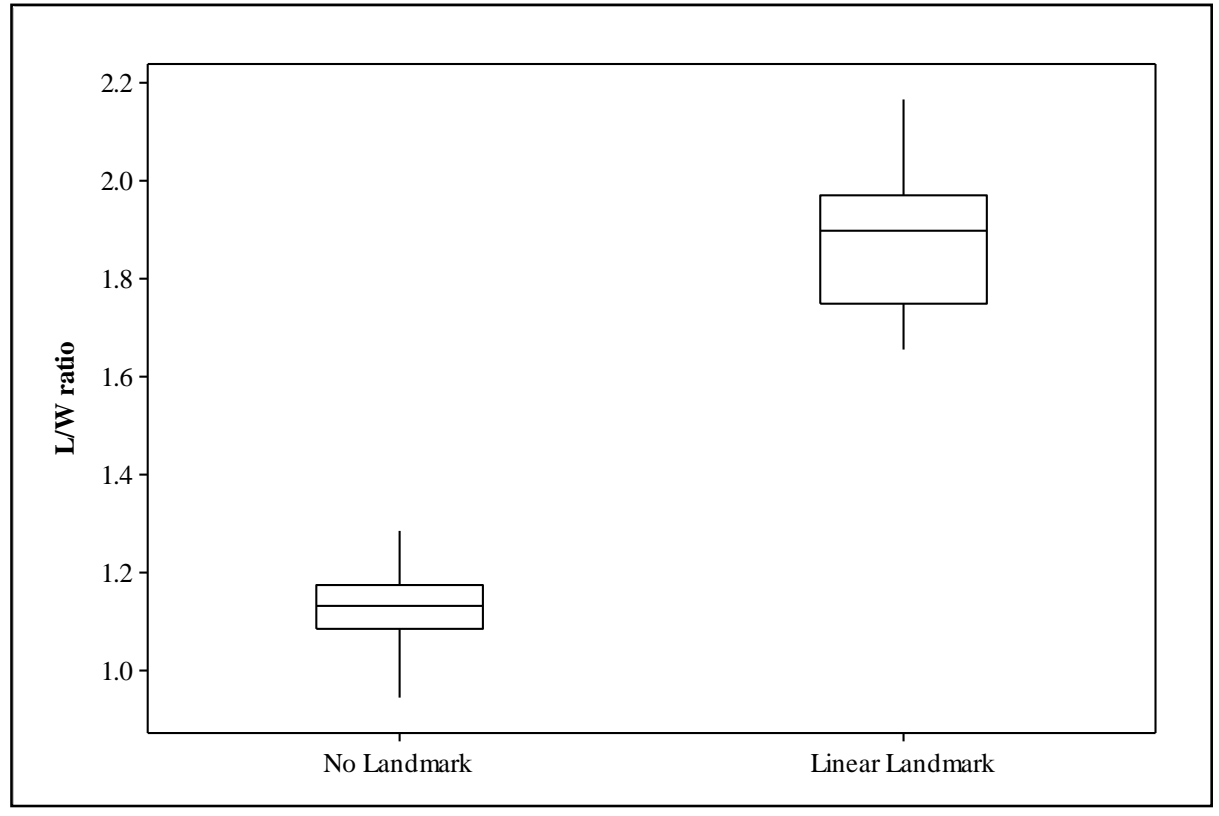

Figure 14b: Territory shape without a landmark and the linear landmark.

A significant change in shape occurred with the presence of a linear landmark. With the landmark, territories were more elongated than when the landmark was absent (Wilcoxon signed-rank test: $\left.\mathrm{W}_{(24)}=0.0, \mathrm{Z}=-4.286, \mathrm{~N}=24, P<0.001\right)$. 


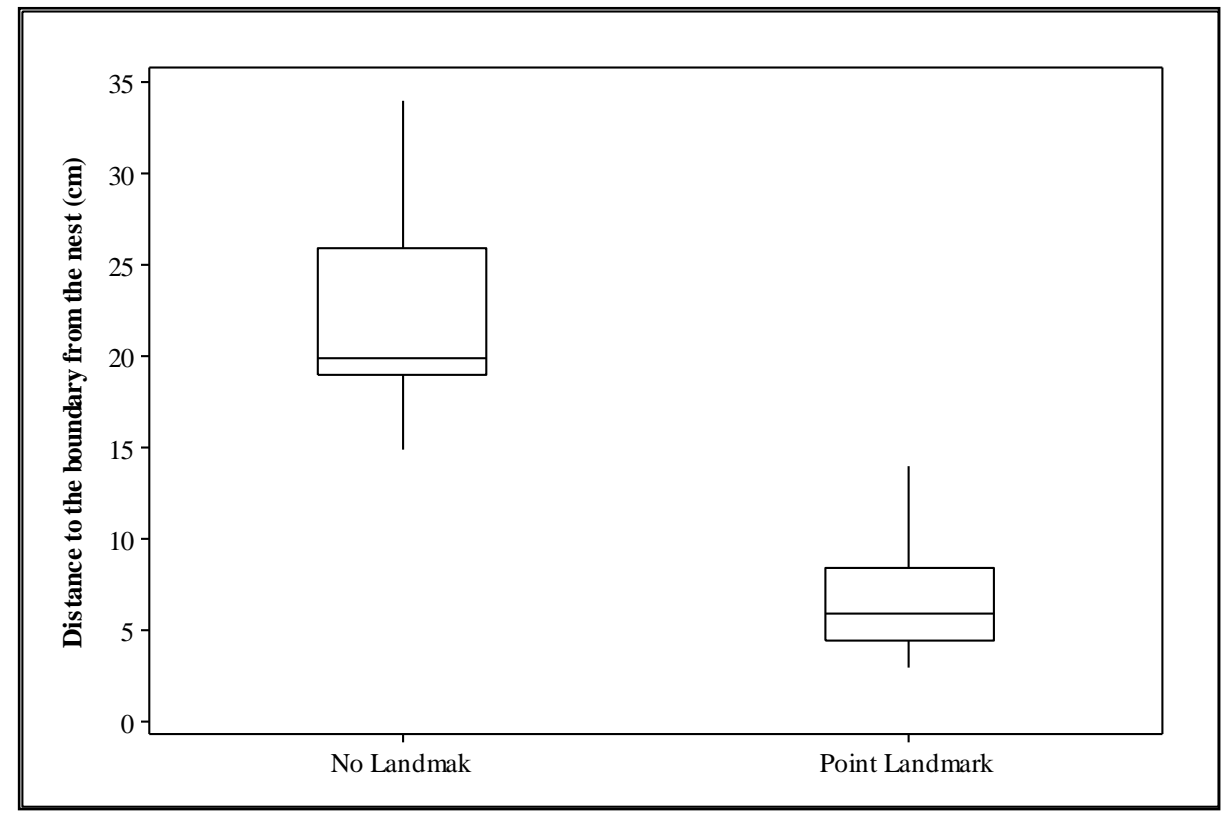

Figure 15a: Distance to the boundary from the nest, with no landmark and the point landmark.

When there was no landmark, the nest was near the center of the territory but convicts moved the boundary closer to the nest when the point landmark was present (Wilcoxon signed-rank test: $\left.\mathrm{W}_{(24)}=1.0, \mathrm{Z}=-4.229, \mathrm{~N}=24, P<0.001\right)$. 


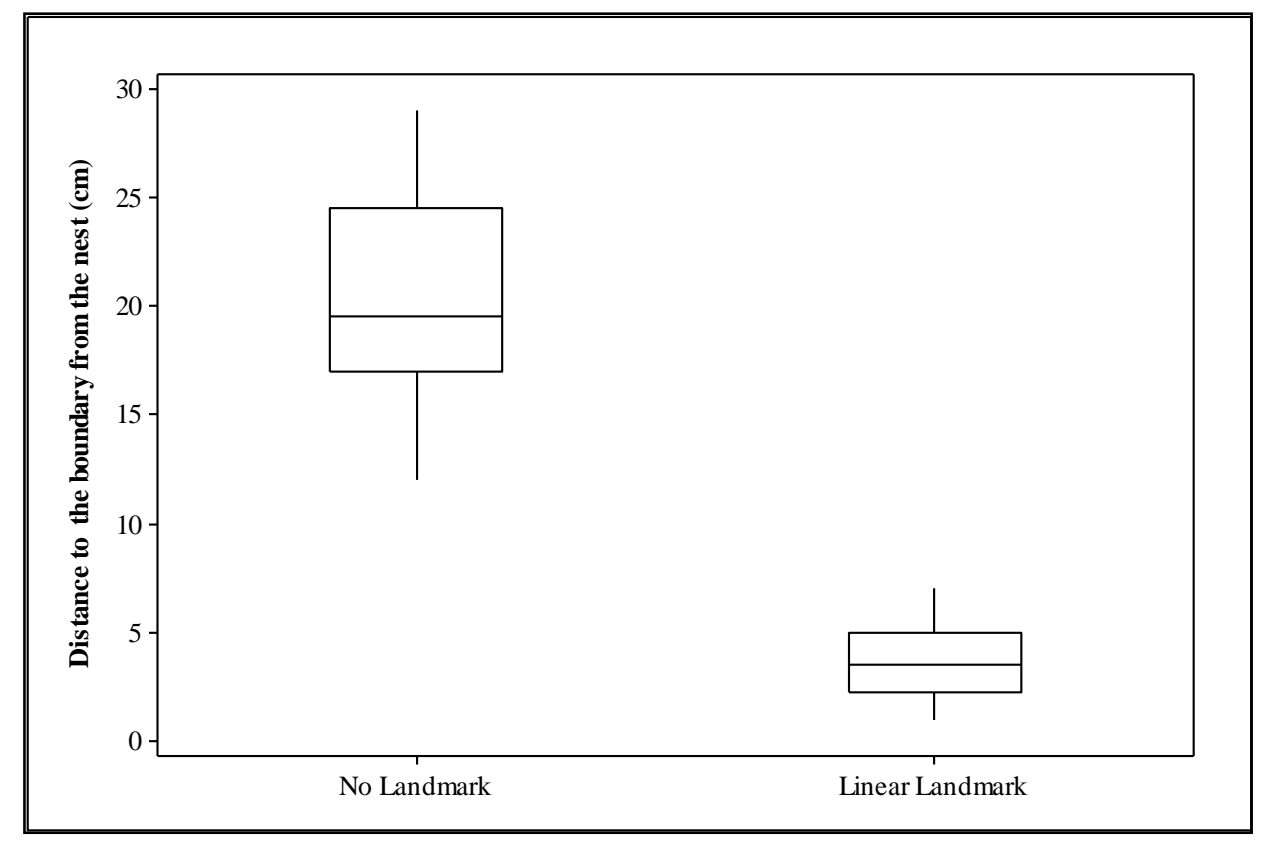

Figure 15b: Distance to the boundary from the nest, with no landmark and with the linear landmark.

Convicts moved the boundary closer to the landmark and the nest when the linear landmark was present (Wilcoxon signed-rank test: $\mathrm{W}_{(24)}=0.0, \mathrm{Z}=-4.286, \mathrm{~N}=24, P<$ $0.001)$. 


\section{CONCLUSION}

The main objective of my dissertation was to investigate how landmarks affect territorial behavior using cichlid fishes as the study species. I first studied how visually

distinctive areas affected gender roles in territorial defense and then examined the effects of landmarks on the landscape of aggression and territory properties. The results of my dissertation clearly demonstrate that landmarks have strong effects on territoriality in cichlid fish, and are likely to have been significant influences on population dynamics and the evolution of the behavior.

In the first chapter, I describe laboratory experiments to investigate how Neolamprologus multifasciatus residents respond to changes in defensive costs. I altered defensive costs by using two different distributions of shells: one in which territories were separated by a visual gap, a distinctive area without shells, and one without a visual gap. This study showed that males and females responded differently to changes in defensive costs, with males being more sensitive to the effect of increased defensive costs. Given that male residents are more likely to respond to male intruders, the increased responsiveness of males could be partly due to males having a stronger tendency to intrude when a visual gap is absent. This study also suggests that, at least in some species, females' contribution to territory defense may vary relatively little regardless of overall costs. This information would have been masked if I had only 
studied agonistic interactions between individuals of one sex, as most studies of territorial behavior have done.

Another finding of this study is that the resource-free, visually distinctive space between territories can function as a visual landmark to reduce the aggression between territorial neighbors. The effects of visually distinctive areas on the behavior of animals are particularly important to investigate because increasing and rapid development and intrusions into natural areas by humans are likely to result in discontinuity in the habitat. For example, the construction of roads across forests creates visually distinctive open patches. Amazonian understory bird flocks were unwilling to cross such open areas and used the man-made roads as their territory boundary (Develey and Stouffer 2001). Interestingly, similar visually distinctive areas are also used by humans to demarcate the political border zones, demilitarized zones and green belts. The significance of resourcefree areas as visual landmarks led to the development of the next two chapters of my dissertation. To broaden the understanding of how these visual landmarks affect territoriality in natural conditions, I conducted two field studies with Hypsophrys nicaraguensis and Amatitilania siquia at Lake Xiloá in Nicaragua.

The second chapter of my dissertation mainly focused on investigating the effects of landmarks on the landscape of agonistic interactions in H. nicaraguensis. In this field study, I used plastic plants as landmarks and recorded aggressive behavior between two conspecific neighbors with and without a landmark at the boundary. During face-offs, which is a challenging behavior seen between neighbors, I found that fish tended to leave a larger area between them when no landmark was present. This larger area between interacting fish may function as a buffer zone to lower defensive costs because it will 
reduce the risk of escalation that may occur as a result of accidental intrusions. The reduction in distance between interacting neighbors in the presence of landmarks indicates that landmarks must be providing the fish with more certainty in identifying the exact location of the boundary and therefore they do not face a greater risk in approaching it. However, leaving a large unused area in the territory could become critical for wildlife managers trying to maintain viable breeding populations under unfavorable environmental conditions. Hence, this study suggests that providing distinct structures such as landmarks could be useful in maximizing the use of space in territorial species. In addition, this work revealed that landmarks are useful in precisely defining territory borders and making fish interact at landmarks when such landmarks are available. These factors may have contributed to lower overall defensive costs by decreasing accidental intrusions, providing easy identification of when an intrusion is occurring, and reducing time spent in boundary patrolling. This is the first field study to experimentally demonstrate that landmarks are useful in clearly defining territory borders.

In my final chapter, I further investigated the effects of landmarks on territoriality, mainly by focusing on the effects of landmarks on fundamental territory properties such as size, shape, and the location of the boundary. Results of the preliminary survey suggested that landmarks could have significant effects on territory size and shape. In the experimental manipulation, I provided empty cans as breeding sites and used plastic plants as landmarks. I observed each pair without landmarks and with either a point landmark or a linear landmark placed near the nest. When landmarks were present, fish set their territorial boundary near the landmark and thus the nest, and territories were 
significantly smaller. With the linear landmark, territories were elongated however, the presence of the point landmark did not alter territories' optimal round shape. The shift in territory boundary demonstrates that fish preferentially situated their boundary at visual landmarks when such landmarks were available. The willingness of fish to move the boundary closer to the nest suggests that landmarked boundaries provide substantial benefits, given that having the boundary near the nest may increase predation risk for fry. The smaller territory size observed in the presence of landmarks suggests that it is more beneficial to defend a smaller territory with well-defined boundaries than a larger territory with undefined territory borders. The reduced size was mainly driven by relocation of the border near the landmark, with pairs giving up an area lacking a clearly defined boundary. This is the first field study to suggest that landmarks could affect both territory size and shape.

The plastic plants I used in this experiment were similar to naturally occurring Chara sp. in the lake. Convicts responded strongly to the presence of these "plants," suggesting that any process, such as eutrophication, that affects the availability of this algae may result in significant modifications in fish behavior and territory properties. The shore line of Lake Xiloá receives a rich influx of phosphorus from laundry detergents, posing a higher risk for future eutrophication.

There has been an ongoing discussion about the functional basis for adopting landmarks as territory boundaries and the findings of this research contribute to this discussion but do not resolve it. The mutual adoption of the same landmark is the main difference between the convention hypothesis and the unilateral advantage hypothesis. It is arguable that $H$. nicaraguensis's territoriality supports the convention hypothesis 
because both neighbors mutually adjust their territorial behavior as a response to the presence of landmarks. However, it is difficult to exclude the unilateral advantage hypothesis because, even in the absence of a contiguous neighbor, A. siquia still rapidly adjusted their territory borders when landmarks were present. Such territory alteration should not have occurred in the absence of neighbors if the convention hypothesis was correct.

Overall, the findings of this study identify several significant features and roles of visual landmarks. First, resource-free areas between territories can function as visual landmarks, which are capable of affecting territorial behavior by lowering defensive costs. My work also demonstrates the sex-related differences in responding to such changes in defensive costs. Second, structures that function as landmarks can alter the landscape of aggression by precisely defining territory borders, reducing the size of defensive boundary zones, and shifting the location where agonistic interactions occur. Third, these landmarks can affect territory properties such as territory size, shape, and boundary location. These findings indicate that territory manipulations are extremely useful in addressing fundamental questions about territory structure and function, the evolution of territoriality, and the role in territoriality in population dynamics. In addition to contributing to the knowledge base of territoriality, findings of this dissertation have important implications for wildlife managers and captive breeders. Utilization of resource-free areas to separate territories could also be applicable for animal welfare, specifically for managing aggressive behavior in captive animals. It also suggests that by providing appropriate habitat features such as visual landmarks, we could maximize the use of space by territorial species and lower the defensive costs of a territory. 
Work described in this dissertation suggests new avenues for investigations into the nature of territorial boundaries and landmarks. Future studies should address the behavioral adjustments associated with landmarks over extended periods of time in order to fully understand landmarks' effects on territorial behavior. Identifying gender-related differences in responding to landmarks will also shed light on the division of roles between members of pairs defending a shared territory. Also, it will be interesting to investigate whether territory-demarcating landmarks are selected and used unilaterally or whether their function is derived by a mutual convention between neighbors under different circumstances. Since a relatively short territorial contest or other aggressive interaction can be energetically costly, it will be interesting to investigate whether selection favors individuals who accept resource-free buffer zones and/or landmarks as designators of a territory boundary. 


\section{REFERENCES}

Adams, E.S. (2001). Approaches to the study of territory size and shape. Annual Review of Ecology and Systematics 32: 277-303

Akin, J.A. (1998). Intra- and inter-sexual aggression in the ground skink (Scincella lateralis). Canadian Journal of Zoology 76: 87-93

Alcock, J. (1983). Post copulatory mate guarding by males of the damselfly of Hetaerina vulnerata selys. Animal Behaviour 30: 99-107

Alonzo, J.J., McKaye, K.R., \& van den Berghe, E.P. (2001). Parental defense of young by the convict cichlid, Archocentrus nigrofasciatus, in Lake Xiloá, Nicaragua. Journal of Aquaculture and Aquatic Sciences 9:208-227

Amundsen, T. (2000). Why are female birds ornamented? Trends in Ecology and Evolution 15: 149-155

Andersson, M. (1978). Optimal foraging area: size and allocation of search effort. Theoretical Population Biology 13: 397-409

Andersson, M. (1994). Sexual selection. Princeton University Press, Princeton

Appleby, B.M., Yamaguchi, N., Johnson, P.J., \& MacDonald, D.W. (1999). Sex-specific territorial responses in tawny owls Strix aluco. Ibis 141: 91-99

Arnott, G., \& Elwood, R.W. (2009). Gender differences in aggressive behavior in convict cichlids. Animal Behaviour 78: 1221-1227

Balshine-Earn, S., \& McAndrew, B.J. (1995). Sex-role reversal in the black-chinned tilapia, Sarotherodon melanotheron (Ruppel) (Cichlidae). Behaviour 132 (11): 861-874

Bard, S.C., Hau, M., Wikelski, M., \& Wingfield, J.C. (2002). Vocal distinctiveness and response to conspecific playback in the spotted antbird, a Neotropical suboscine. Condor 104: 387-394

Barker, D.G., Murphy, J.B., \& Smith, K.W. (1979). Social behavior in a captive group of Indian pythons, Python molurus with formation of a linear social hierarchy. Copeia 1979: $466-471$ 
Barlow, G.W. (1976). The Midas cichlid in Nicaragua. In: Investigations of the Ichthyofanua of Nicaraguan Lakes. (ed. Thorson, T. B.), pp. 333-358. Lincoln, NE: University of Nebraska Press

Barlow, G. W., Baylis, J. R., \& Roberts D. (1976). Chemical analyses of some crater lakes in relation to adjacent Lake Nicaragua. In Investigations of the ichthyology of Nicaraguan lakes (ed. Thorson, T. B.), pp. 17-20. Lincoln, NE: University of Nebraska Press

Barlow, G.W. (2000). The cichlid fishes: nature's grand experiment in evolution. Cambridge, MA: Perseus Publishing

Baylis, J.R. (1974). The behavior and ecology of Herotilapia multispinosa (Teleostei, Cichlidae). In Investigations of the ichthyology of Nicaraguan lakes (ed. Thorson, T. B.), pp. 477-508. Lincoln, NE: University of Nebraska Press

Bergmueller, R., \& Taborsky, M. (2005). Experimental manipulation of helping in a cooperative breeder: helpers 'pay to stay' by pre-emptive appeasement. Animal Behaviour 69: $19-28$

Both, C., \& Visser, M.E. (2000). Breeding territory size affects fitness: an experimental study on competition at the individual level. Journal of Animal Ecology 69:1021-1030

Brandtmann, G., Scandura, M., \& Trillmich, F. (1999). Female-female conflict in the harem of a snail cichlid (Lamprologus ocellatus): Behavioral interactions and fitness consequences. Behaviour 136: 1123-1144

Breau, C., \& Grant, J.W.A. (2002). Manipulating territory size via vegetation structure: Optimal size of area guarded by the convict cichlid (Pisces, Cichlidae). Canadian Journal of Zoology 80: 376-380

Brown, J. L. (1964). The evolution of diversity in avian territorial systems. Wilson Bulletin 76:160-169

Busch, D.S., Wingfield, J.C., \& Moore, I.T. (2004). Territorial aggression of a tropical passerine, Zonotrichia capensis, in response to variety of conspecific intruders. Behaviour 141: 1173-1188

Buss, D.M. (2005). The Handbook of Evolutionary Psychology. Wiley, New York

Carpenter, F.L. (1983). Pollination energetics in avian communities: simple concepts and complex realities. In Handbook of experimental pollination biology (eds. Jones, E.C., \& Little, R.J.), pp. 215-234. Van Nostrand Reinhold, New York 
Chellappa, S., \& Huntingford, F.A. (1989). Depletion of energy reserves during reproductive aggression in male three-spined stickleback, Gasterostem aculeatus L. Journal of Fish Biology 35: 315-316

Chellappa, S., Huntingford, F.A., Strang, R.H.C., \& Thompson, R.Y. (1989). Annual variation in energy reserves in male three-spined stickleback, Gasterosteus aculeatus L. Journal of Fish Biology 35: 275-286

Clayton, D.A. (1987). Why mudskippers build walls. Behaviour 102(3-4): 185-195 Cleveland, A. (1999). Energetic costs of agonistic behavior in two herbivorous damselfishes (Stegastes). Copeia 1999: 857-867

Coie, J.D., \& Dodge, K.A. (1997). Aggression and antisocial behavior. In Handbook of Child Psychology (eds. Damon, W. \& Eisenberg, N.), pp. 779-862. Wiley, New York

Craig, J.L. (1979). Habitat variation in the social organization of a communal gallinule, the pukeko, Porphyrio porphyrio melanotus. Behavioral Ecology and Sociobiology 5: $331-358$

Craig, P. (1996). Intertidal territoriality and time-budget of the surgeonfish, Acanthurus lineatus, in American Samoa. Environmeantal Biology of Fishes 46: 27-36

Davies, N.B. (1978). Territorial defense in the speckled wood butterfly (Pararge aegeria): The resident always wins. Animal Behaviour 26: 138-147

Davies, N.B., \& Houston, A.I. (1984). Territory economics. In Behavioural ecology, 2nd edition (eds. Krebs, J.R., \& Davies, N.B.), Blackwell, Oxford

Develey, P.F., \& Stouffer, P.C. (2001). Effects of Roads on Movements by Understory Birds in Mixed-Species Flocks in CentralAmazonian Brazil. Conservation Biolog15 (5): $1416-1422$

Dill, L. (1978). An energy-based model of optimal feeding territory size. Theoritical Population Biology 14: 396-429

Dittmann, M., Roesti, M., Indermaur, A., Colombo, M., Gschwind, M., Keller, I., Kovac, R., Barluenga, M., Muschick, M., \& Salzburger, W. (2012). Depth-dependent abundance of Midas Cichlid fish (Amphilophusspp.) in two Nicaraguan crater lakes. Hydrobiologia 686 (1): $277-285$

Draud, M., \& Lynch, P.A.E. (2002). Asymmetric contests for breeding sites between monogamous pairs of convict cichlids (Archocentrus nigrofasciatum, Cichlidae): pair experience pays. Behaviour 139: 861-873 
Draud, M., Macias-Ordonez, R., Verga, J., \& Itzkowitz, M. (2004). Female and male Texas cichlids (Herichthys cyanoguttatum) do not fight by the same rules. Behavioral Ecology 2004: 102-108

Eason, P. (1992). Optimization of territory shape in heterogeneous habitats: a field study of the red-capped cardinal (Paroaria gularis). Journal of Animal Ecology 61: 411-424

Eason, P.K., \& Stamps, J.A., (1992). The effect of visibility on territory size and shape. Behavioural Ecology 3: 166-172

Eason, P., \& Hannon, S.J. (1994). New birds on the block-new neighbors increase defensive costs for territorial male willow ptarmigan. Behavioral Ecology and Sociobiology 34: 419-426

Eason, P.K., Cobbs, G.A., \& Trinca, K.G. (1999). The use of landmarks to define territorial boundaries. Animal Behaviour 58: 85-91

Eason, P.K., \& Stamps, J.A. (2001). The effect of visibility on space use by territorial red-capped cardinals. Behaviour 138: 19-30

Eason, P.K., \& Hannon, S.J. (2003). Effect of pairing status on use of space by territorial willow ptarmigan (Lagopus lagopus): bachelor males choose life on the edge. Auk 120: 497-504

Eberhard, J.R., \& Ewald, P.W. (1994). Food availability, intrusion pressure, and territory size: an experimental study of Anna's Hummingbirds (Calypte anna). Behavioural Ecology and Sociobiology 34:11-18

Fedy, B.C., \& Stutchbury, B.J.M. (2005). Territory defense in tropical birds: females as aggressive as males? Behavioural Ecology and Sociobiology 58: 414-422

Ficken, M.S. (1962). Agonistic behavior and territory in the American redstart. Auk 79: 607-632

Fordm, R. (1983). Home range in a patchy environment: optimal foraging predictions. American Zoologist 23: 315-326

Foster, M.S. (1981). Cooperative behavior and social organization of the swallow-tailed manakin (Chiroxiphia caudate) Behavioural Ecology and Sociobiology 9: 167-77

Galeotti, P., Sacchi, R., \& Perni, E. (1997). Cooperative defense and intrasexual aggression in scops owls (Otus scops): Responses to playback male and female calls. Journal of Raptor Research 31(4): 353-35

Getty, T. (1981). Analysis of central-place space use patterns: the elastic disc revisited. Ecology 62: 907-914 
Gill, F.B., \& Wolf, L.L. (1975). Economics of feeding territoriality in the Golden-winged Sunbird. Ecology 56:333-345

Goodenough, J., McGuire, J., \& Jakob, E. (2009). Perspectives in animal behavior. $3^{\text {rd }}$ ed. J Wiley \& Sons

Gosling, L.M., \& Roberts, S.C. (2001). Scent-marking by male mammals: cheat-proof signals to competitors and mates. Advances in the Study of Behaviour 30: 169-217

Goubault, M., Mack, A. F.S., \& Hardy, I.C.W. (2007). Encountering competitors reduces clutch size and increases offspring size in a parasitoid with female-female fighting. Proceedings of the Royal Society B: Biology 274: 2571-2577

Grant, P.R. (1968). Polyhedral territories of animals. American Naturalist 102: 75-80

Hack, M.A. (1997). The energetic costs of fighting in the house cricket, Acheta domesticus L. Behavioural Ecology 8: 28-36

Hall, M.L. (2000). The function of duetting in magpie-larks: conflict, cooperation, or commitment? Animal Behaviour 60: 667-677

Hamelin, F., \& Lewis, M.A. (2010). A differential game theoretical analysis of mechanistic models for territoriality. Journal of Mathematical Biology 61:665-694

Hamilton, I.M., Heg, D., \& Bender, N. (2005). Size differences within a dominance hierarchy influence conflict and help in a cooperatively breeding cichlid. Behaviour 142: $1591-1613$

Hand, J.L. (1986). Territory defense and associated vocalizations of a western gulls. Field Ornithology 57:1-15

Harding, J.A., Almany, G.R., Houck, L.D., \& Hixon, M.A. (2003). Experimental analysis of monogamy in the Caribbean cleaner goby, Gobiosoma evelynae. Animal Behaviour 65: $865-874$

Heap, S., Byrne, P., \& Stuart-Fox, D. (2012). The adoption of landmarks for territorial boundaries. Animal Behaviour 83: 871-878

Hinde, R.A. (1956). The biological significance of the territories of birds. Ibis 98:340369

Hixon, M. (1980). Food production and competitor density as the determinants of feeding territory size. American Naturalist 115: 510-530 
Hixon, M. A. (1981). An experimental analysis of territoriality in the California reef fish Embiotoca jacksoni (Embiotocidae). Copeia 1981: 653-665

Hixon, M.A., Carpenter, F.L., \& Paton, D.C. (1983). Territory area, flower density, and time budgeting in hummingbirds: an experimental and theoretical analysis. American Naturalist 122: 366-391

Huntingford, F., \& Turner, A. (1987). Animal Conflict. Chapman \& Hall, London

Itzkowitz, M. (1984). Parental division of labor in a monogamous fish. Behaviour 89: $251-260$

Itzkowitz, M. (1985). Sexual differences in offspring defense in a monogamous cichlid fish. Zeitschrift fur Tierpsychologie 70:247-255

Itzkowitz, M., \& Nyby, J. (1982). Field observations of parental behavior of the Texas cichlid Cichlasoma cyanoguttatum. American Midland Naturalist 108:364- 368

Itzkowitz, M., Santangelo, N., Cleveland, A., Bockelman, A., \& Richter, M. (2005). Is the selection of sex-typical parental roles based on an assessment process? A test in the monogamous convict cichlid fish. Animal Behaviour 69: 95-105

Jaeger, R.G., Nishikawa, K.C.B., \& Barnard, D.E. (1983). Foraging tactics of a terrestrial salamander: cost of territorial defense. Animal Behaviour 31: 191-98

Keeley, E.R. (2000). An experimental analysis of territory size in juvenile steelhead trout. Animal Behaviour 59:477-90

Keenleyside, M.H. (1991). Cichlid fishes: Behavior, Ecology and Evolution. (pp 1-35). New York: Chapman and Hall

Keenleyside, M.H.A., Baileym R.C., \& Young, V.H. (1990). Variation in the mating system and associated parental behavior of captive and free-living Cichlasoma nigrofasciatum (Pisces, Cichlidae). Behaviour 112:202-221

Kluge, A.G. (1981). The life history, social organization and parental behavior of a Hyla rosenbergi a nest-building gladiator frog. Miscellaneous publications / University of Michigan, Museum of Zoology160:1-170

Kodric-Brown, A. (1978). Establishment and defense of breeding territories in a pupfish (Cyprinodontidae: Cyprinodon). Animal Behaviour 26:818-834

Kohler, U. (1997). Zur struktur und evolution des sozialsystems von Neolamprologus multifasciatus (Cichlidae, Pices), dem kleinsten schneckenbuntbarsch des Tanganjikasees. Disseratation, Ludwig-Maximilians-Universität München 
Kokko, H., \& Sutherland, W. J. (1998). Optimal floating and queuing strategies: consequences for density dependence and habitat loss. American Naturalist 152:354-366

Kruuk, H. (1978). Spatial organization and territorial behaviour of the European badger (Meles meles). Journal of Zoology (London) 184: 1-19

LaManna, J.R., \& Eason, P.K. (2003). Effects of landmarks on territorial establishment. Animal Behaviour 65: 471-478

Lamberson, R.H., Noon, B.R., Voss, C., \& McKelvey, K.S. (1994). Reserve Design for Territorial Species: The Effects of Patch Size and Spacing on the Viability of the Northern Spotted Owl Conservation Biology 8: 185-195

Lehtonen, T.K., Wong, B.B.M., Lindström, K. \& Meyer, A. (2011). Species divergence and seasonal succession in rates of mate desertion in closely related Neotropical cichlid fishes. Behavioural Ecology Sociobiolgy 65: 607-612

Levin, R.N. (1996b). Song behavior and reproductive strategies in a duetting wren, Thryothorus nigricapillus: II. Playback experiments. Animal Behaviour 52: 1107-1117

Lewis, M., \& Moorcroft, P. (2001). ESS analysis of mechanistic models for territoriality: the value of scent marks in spatial resource partitioning. Journal of Theoretical Biology 210:449-461

Lim, T.M., McKaye, K.R., \& Weiland, D.J. (1976). An investigation into the use of artificial habitats as a means of increasing the fishery productivity of the great lakes complex of Nicaragua, Central America. In Investigations of the Ichthyofauna of Nicaraguan Lakes (ed.Thorson, T. B.), pp. 311-320. Univ. Nebraska, Lincoln, Nebraska

Logue, D.M., \& Gammon, D.E. (2004). Duet song and sex roles during territory defense in a tropical bird, the black-bellied wren, Thryothorus fasciatoventris. Animal Behaviour 68: 721-731

Maccoby, E.E., \& Jacklin, C.N. (1974). The psychology of sex differences. Stanford University Press, Stanford

Mares, M.A., Lacher, T.E., Willig, M.R., Bitar, N.A., Adams, R., Klinger, A., \& Tazik, D. (1982). An experimental analysis of social spacing in Tamias striatus. Ecology 63: $267-273$

Marler, C.A., \& Moore, C.M. (1989). Time and energy costs of aggression in testosterone implanted free-living male mountain spiny lizards (Sceloporus jarrovi). Physiological Zoology 62: 1334-1350

Maynard Smith, J. (1982). Evolution and the Theory of Games. Cambridge: Cambridge University Press 
McKaye, K.R. (1977). Competition for breeding sites between the cichlid fishes of Lake Jiloá, Nicaragua. Ecology 58: 291-302

McKaye, K.R. (1984). Behavioural aspects of cichlid reproductive strategies: patterns of territoriality and brood defense in Central American substratum spawners versus African mouth brooders. In Fish reproduction: strategies and tactics (eds. Wootton, R. J., \& Potts, C. W.), pp. 245-273. Academic Press, London

McKaye, K.R. (1986). Mate choice and size assortative pairing by the cichlid fishes of Lake Jiloa, Nicaragua.Journal of Fish Biology 29 (Supp. A); 135-150

Meral, G.H. (1973). The adaptive significance of territoriality in New World Cichlidae. Ph.D. thesis, University of California, Berkeley

Mesterton-Gibbons ,M. \&Adams, E.S. (2003). Landmarks in territory partitioning: a strategically stable convention? American Naturalist 161(5):685-689

Meyer, A. (in press). King Midas and his many extremely young species: Studies on speciation in Cichlid fishes in Nicaraguan crater cakes. In: In the Light of Evolution: Essays from the Laboratory and the Field (ed. Roberts, L.J)

Miller, E.H. (1974). Walrus ethology I. The social role of tusks and applications of multidimensional scaling. Canadian Journal of Zoology 53: 590-613

Mohr, C.O. (1947). Table of equivalent populations of North American small mammals. American Midland Naturalist 37: 223-249

Moorcroft, P.R., \& Lewis, M.A. (2006). Mechanistic home range analysis. Princeton University Press, Princeton

Morrell, L.J., \& Kokko, H. (2005). Bridging the gap between mechanistic and adaptive explanations of territoriality. Behavioural Ecology and Sociobiology 57:381-390

Morton, E.S., \& Derrickson, K.C. (1996). Song ranging by the dusky antbird, Cercomarca tyrannia: ranging without song learning. Behavioural Ecology and Sociobiology 39: 195-201

Nakano, S., \& Nagoshi, M. (1990). Brood defense and parental roles in a biparental cichlid fish Lamprologus toae in Lake Tanganyika. Japanese Journal of Ichthyology 36: $468-476$

Pelletier, T. (2008). Development of a new model system for studies of the economic theory of territoriality: Neolamprologus multifasciatus. MS Thesis, University of Louisville 
Pereira, H.M., Bergmann, A., \&Roughgarden, J. (2003). Socially stable territories: the negotiation of space by interacting foragers. American Naturalist 161 (1): 143-152

Petersen, G., \& Hardy, I.C.W. (1996). The importance of being larger: parasitoid intruder-owner contests and their implications for clutch size. Animal Behaviour 51: $1363-1373$

Potter, P.E. (1972). Territorial behavior in Savannah sparrows in southeastern Michigan. Wilson Bulletin 84: 48-59

Quinard, A., \& Cezilly, F. (2012). Sex roles during conspecific territorial defense in Zenaida dove, Zenaida aurita. Animal Behaviour 83: 47-54

Reid, M.L., \&Weatherhead, P.J. (1988). Topographical constraints on competition for territories. Oikos 51:115-17

Riechert, S.E. (1988). The energetic costs of fighting. American Zoologist 28: 877-884

Riedel, D.R. (1964). Informe al gobierno de Nicaragua sobre mejoramiento de las tecnicas de pesca en el Lago de Managua yotras aguas continentales, 1961-1962. Informe FAO 1885:1-46

Rollo, L.D., \& Wellington, W.G. (1979). Intra- and Inter-specific agonistic behavior among terrestrial slugs (Pulmonata, Stylommatophora) Canadian Jouranl of Zoology 57: 846-51

Rolstad, J. (1991). Consequences of forest fragmentation for the dynamics of bird populations: conceptual issues and the evidence. Biological Journal of the Linnaean Society 42:149-163

Salomonson, M.G., \& Balda, R.P. (1977). Winter territoriality of Townsend's Solitaires (Myadestes townsendi) in a pinyon-juniper-ponderosa pine ecotone. Condor 79:148- 161

Sato, T., \& Gashagaza, M.M. (1997). Shell-brooding cichlid fishes of Lake Tanganyika: their habitats and mating systems. In: Fish communities in Lake Tanganyika (eds.

Kawanabe, H., Hori, M., \& Nagoshi , M.), pp. 221-240. Kyoto University Press, Kyoto

Schoener, T.W. (1983). Simple models of optimal feeding territory size: a reconciliation. American Naturalist 121, 608-629

Schradin. C., \& Lamprecht, J. (2000). Female-biased immigration and male peacekeeping in groups of the shell-dwelling cichlid fish Neolamprologus multifasciatus. Behavioural Ecology and Sociobiology 48 (3): 236-242

Schradin, C., \& Lamprecht, J. (2002). Causes of female emigration in the group-living cichlid fish Neolamprologus multifasciatus. Ethology 108(3): 237-248 
Sherman, P.T., \& Eason, P.K. (1998). Size determinants in territories with inflexible boundaries: manipulation experiments on white-winged trumpeters' territories.

Ecology 79: 1147-1159

Smith, C. (2011). Good fences make good neighbours: the role of landmarks in territory partitioning in the rose bitterling (Rhodeus ocellatus). Behaviour 148: 233-246

Smith, C., \& Wootton, R.J. (1999). Parental energy expenditure of the male three-spined stickleback. Journal of Fish Biology 54: 1132-1136

Smith, C., Reichard, M., Douglas, A., \& Jurajda, P. (2006). Population consequences of behaviour in the European bitterling (Rhodeus sericeus Cyprinidae). - Ecology of Freshwater Fishes 15: 139-145

Smith, C., Reynolds, J.D., \& Sutherland, W.J. (2000). The population consequences of reproductive decisions. Proceedings of Royal Society of London B: Biology 267: 13271334

Smith, C.C. (1968). The adaptive nature of social organization in the genus of three squirrels Taniiasciiirus. Ecological Monographs 38: 31-63

Smith. C., \& Wootton, R.J. (1995). The costs of parental care in teleost fishes. Reviews in Fish Biology and Fisheries 5:7-22

Smith-Grayton, P. K., \& Keenleyside, M.H.A. (1978). Male-female roles in Heterotilapia multispinosa (Pisces: Cichlidae). Animal Behaviour 26: 520-526

Snekser, J., Santangelo N., \& Itzkowitz. M. (2011). Sex differences in biparental care as offspring develop: a field study of convict cichlids (Amatitlania siquia). Environmental Biology of Fishes 91:15-25

Sogge, M.K., Koronkiewiczi, T.J., Van Riper III, C., \& Durst, S.L. (2007). Willow flycatcher nonbreeding territory defense behavior in Cost Rica. Condor 109:475-480

Spence, R., \& Smith, C. (2006). Female mate preferences in the zebrafish (Danio rerio). Behavioural Ecology 17: 779-783

Stamps, J.A. (1990). The effect of contender pressure on territory size and overlap in seasonally territorial species. American Naturalist 135 (5): 614-632

Stamps, J. A. (1994). Territorial behavior: testing the assumptions. In: Advances in the Study of Behavior (eds. Slater, P. J. B., Rosenblatt, J. S., Snowden, C. T., \& Milinski, M. M.), Vol. 23 pp. 173-232. Academic Press, San Diego, CA 
Stamps, J.A. (1998). Territoriality. In: Comparative psychology: A handbook. (eds. Greenburg, G., \& Haraway, M.M.), pp. 761-770. Garland Publishing, New York

Stiassny, M.L.J. (1991). Phylogenetic relationships of the family Cichlidae: an overview. In; Cichlid Fishes: behaviour, ecology and evolution. (ed. Keenleyside, M.H.A.), pp. 135. Chapman Hall, London

Stiassny, M.L.J. (1994). A tangled web: Cichlids and their relatives. Cichlids yearbook, 4: $91-94$

St-Louis, V., M. Fortin, \& Desrochers, A. (2004). Spatial association between forest heterogeneity and breeding territory boundaries of two forest songbirds. Landscape Ecology 19:591-601

Sullivan, T.P., \& Klenner, W. (1992). Response to Koford: red squirrels and supplemental feeding. Journal of Mammalogy 73: 933-936

Thresher, R.E. (1979). Field analysis of territoriality of three-spot damselfish Eupomacentrus planifrons. Copeia 266-75

Van den Assem, J. (1967). Territory in the three-spined stickleback Gasterosteus aculeatus L: an experimental study in intra-specific competition. Behavioural Supplement 16: $1-164$

Villa, J. (1968). Una teoria sobre el origen de los peces de Xilmi. Rev Univ Centro Amer $1: 202-214$

Welsh, D.A. (1975). Savannah sparrow breeding and territoriality on a Nova Scotia dune beach. Auk 92: 235-251

Wilkin, T.A., Garant, D., Gosler, A.G., \& Sheldon, B.C. (2006). Density effects on lifehistory traits in a wild population of the great tit Parus major: analyses of long-term data with GIS techniques. Journal of Animal Ecology 75(2):604-15

Wisenden, B.D. (1994). Factors affecting mate desertion by males in free-ranging convict cichlids (Cichlasoma nigrofasciatum). Behavioural Ecology 5: 439-447

Wisenden, B.D. (1995). Reproductive behaviour in free-ranging convict cichlids, Cichlasoma nigrofasciatum. Environmental Biology of Fishes 43:121-134

Wisenden, B.D., \& Dye, T.P. ( 2009). Young convict cichlids use visual information to update olfactory homing cues. Behavioural Ecology and Sociobiology 63: 443-449

Wisenden, B.D., Snekser, J.L., Stumbo, A.D., \& Leese, J.M. (2008). Parental defense of an empty nest after catastrophic brood loss. Animal Behaviour 76: 2059-2067 
Zegers, D.A. (1981). Time budgets of Wyoming ground squirrels, Spermophilus elegans.

Great Basin Naturalist 41:221-228 


\section{APPENDIX I}

Statistics for combining data in point landmark and linear landmark treatments.

\begin{tabular}{|c|c|c|c|c|c|}
\hline Treatment & Condition & Order & Shape & Size $\left(\mathrm{cm}^{2}\right)$ & $\begin{array}{l}\text { Distance to the } \\
\text { boundary from } \\
\text { the nest }(\mathrm{cm})\end{array}$ \\
\hline \multirow[t]{4}{*}{$\begin{array}{l}\text { Point } \\
\text { landmark }\end{array}$} & \multirow[t]{2}{*}{$\begin{array}{l}\text { Point } \\
\text { landmark }\end{array}$} & $\begin{array}{l}\text { Landmark } \\
1^{\text {st }}\end{array}$ & $1.16 \pm 0.10$ & $\begin{array}{r}2401.82 \\
\pm 493.73 \\
\end{array}$ & $15.08 \pm 0.01$ \\
\hline & & $\begin{array}{l}\text { Landmark } \\
2^{\mathrm{n}}\end{array}$ & $\begin{array}{l}1.19 \pm 0.02 \\
\text { (Mann-Whitney } \\
\text { U test: } \\
\mathrm{U}_{(22)}=150.0, \\
\mathrm{P}=1.000)\end{array}$ & $\begin{array}{l}2376.49 \\
\pm 442.07 \\
\text { (Mann-Whitney } U \\
\text { test: } \mathrm{U}_{(22)}=149.0, \\
\mathrm{P}=0.977)\end{array}$ & $\begin{array}{l}13.77 \pm 0.01 \\
\text { (Mann-Whitney } \mathrm{U} \\
\text { test: } \mathrm{U}_{(22)}=150.0, \\
\mathrm{P}=1.000)\end{array}$ \\
\hline & \multirow[t]{2}{*}{$\begin{array}{l}\text { No } \\
\text { landmark }\end{array}$} & $\begin{array}{l}\text { Landmark } \\
1^{\text {st }}\end{array}$ & $1.15 \pm 0.63$ & $\begin{array}{r}2965.03 \\
+539.92 \\
\end{array}$ & $29.92 \pm 0.45$ \\
\hline & & $\begin{array}{l}\text { Landmark } \\
2^{\text {nd }}\end{array}$ & $\begin{array}{l}1.14 \pm 0.10 \\
\text { (Mann-Whitney } \\
U \text { test: } \\
\mathrm{U}_{(22)}=149.5, \\
\mathrm{P}=0.744)\end{array}$ & $\begin{array}{l}2869.44 \\
\pm 402.02 \\
\text { (Mann-Whitney U } \\
\text { test: } U_{(22)}=150.0, \\
P=1.000)\end{array}$ & $\begin{array}{l}28.54 \pm 0.68 \\
\text { (Mann-Whitney } \mathrm{U} \\
\text { test: } \mathrm{U}_{(22)}=130.5, \\
\mathrm{P}=0.270)\end{array}$ \\
\hline \multirow[t]{4}{*}{$\begin{array}{l}\text { Linear } \\
\text { landmark }\end{array}$} & \multirow[t]{2}{*}{$\begin{array}{l}\text { Linear } \\
\text { landmark }\end{array}$} & $\begin{array}{l}\text { Landmark } \\
1^{\text {st }}\end{array}$ & $1.87 \pm 0.71$ & $\begin{array}{r}1504.53 \\
\pm 104.73 \\
\end{array}$ & $9.75 \pm 0.36$ \\
\hline & & $\begin{array}{l}\text { Landmark } \\
2^{\text {nd }}\end{array}$ & $\begin{array}{l}1.86 \pm 0.20 \\
\text { (Mann-Whitney } \\
\text { U test: } \\
\mathrm{U}_{(22)}=153.5, \\
\mathrm{P}=0.862)\end{array}$ & $\begin{array}{l}1665.82 \\
\pm 189.04 \\
\text { (Mann-Whitney } U \\
\text { test: } U_{(22)}=148.0, \\
P=0.417)\end{array}$ & $\begin{array}{l}9.75 \pm 0.34 \\
\text { (Mann-Whitney } \mathrm{U} \\
\text { test: } \mathrm{U}_{(22)}=148.5, \\
\mathrm{P}=0.953)\end{array}$ \\
\hline & \multirow[t]{2}{*}{$\begin{array}{l}\text { No } \\
\text { landmark }\end{array}$} & $\begin{array}{l}\text { Landmark } \\
1^{\text {st }}\end{array}$ & $1.16 \pm 0.36$ & $\begin{array}{r}1902.50 \\
\pm 167.21 \\
\end{array}$ & $24.33 \pm 0.05$ \\
\hline & & $\begin{array}{l}\text { Landmark } \\
2^{\text {nd }}\end{array}$ & $\begin{array}{l}1.11 \pm 0.62 \\
\text { (Mann-Whitney } \\
\text { U test: } \\
\mathrm{U}_{(22)}=125.0, \\
\mathrm{P}=0.157)\end{array}$ & $\begin{array}{l}2446.68 \\
\pm 424.50 \\
\text { (Mann-Whitney } \mathrm{U} \\
\text { test: } \mathrm{U}(22)=143.0, \\
\mathrm{P}=0.708)\end{array}$ & $\begin{array}{l}28.75 \pm 0.10 \\
\text { Mann-Whitney } \mathrm{U} \\
\text { test: } \mathrm{U}_{(22)}=122.0, \\
\mathrm{P}=0.110)\end{array}$ \\
\hline
\end{tabular}




\title{
CURRICULUM VITAE
}

\author{
PIYUMIKA S SURIYAMPOLA \\ DEPARTMENT OF BIOLOGY \\ UNIVERSITY OF LOUISVILLE \\ LOUISVILLE, KY. \\ pssoor01@louisville.edu \\ (502) 403-0938
}

\section{EDUCATION}

2008- Present PhD in Biology: Ecology, Evolution and Behavior

(Anticipated graduation December 2013)

University of Louisville, Louisville, KY

$2013 \quad$ MS in Biology

University of Louisville, Louisville, KY

2002- 2006 BSc in Zoology (First Class Honors) with minor in Molecular Biology University of Peradeniya, Sri Lanka

\section{RESEARCH INTERESTS}

- Behavioral ecology of territoriality and parental care in vertebrates

- Acoustic communication in aquatic organisms

- Conservation and sustainable use

\section{RESEARCH EXPERIENCE}

2011-2013 Effects of landmarks on territorial behavior of cichlid fish in Lake Xiloá, Nicaragua

Supervisor: Dr. Perri Eason, Department of Biology, University of Louisville 
2012 Effects of size asymmetry on aggression and acoustic communication in captive Skunk Loach, Yasuhikotakia morleti

Supervisor: Dr. Perri Eason, Department of Biology, University of Louisville

2009 - 2011 Laboratory experiments on sex differences in territorial behavior in African cichlid, Neolamprologus multifaciatus

Supervisor: Dr. Perri Eason, Department of Biology, University of Louisville

2008 Anacardic acid inhibition of breast cancer cell proliferation Supervisor: Dr. Carolyn Klinge, Department of Biochemistry and Molecular Biology, University of Louisville

2007-2008 Laboratory study to investigate personality traits of mealworm beetles Supervisor: Dr. Perri Eason, Department of Biology, University of Louisville

2005-2006 Field study on the ecology and population dynamics of Western Ceylon Palm squirrel (Funambulance palmarum favonicus) in Kandy District, Sri Lanka

Supervisor: Dr. Padma De Silva, Department of Zoology, University of Peradeniya, Sri Lanka

\section{TEACHING EXPERIENCE}

\section{Teaching Biology}

2008 - 2013 Graduate Teaching Assistant: Department of Biology, University of Louisville

Labs taught: Principles of Biology, Introduction to Biology

2006 - 2007 Graduate Teaching Assistant: Department of Zoology, University of Peradeniya

Labs taught: Comparative Anatomy and Animal Physiology, Functional Histology, Mammalian Biology, Basic Ecology

\section{Science Education}

Instructor Assistant: Advanced Placement Program for Biology teachers. University of Louisville 
2007 Teaching Instructor: Science Camp GCE A/L students, Science Education Unit, University of Peradeniya

2006 Teaching instructor: Workshop for GCE A/L Teachers in Biology in Uva Province, Science Education unit, University of Peradeniya

2006 Teaching instructor: Workshop for GCE A/L Teachers in Biology in Central Province, Science Education unit, University of Peradeniya

\section{Professional Training}

2011- 2012 Graduate of Graduate Teaching Academy: Delphi Center, University of Louisville

\section{STUDENT MENTORING}

2011- 2013 Supervised and trained Undergraduate Teaching Assistants in Principals of Biology lab:

Brett Allen, Joseph Lacasse, Courtney Jenny, Jared Andrews, Lauren Poole, Deepa Patel, Taylor Forns, Dirk Dorsal

2008 - 2012 Undergraduate student researchers supervised:

Jeremy Harbour, Christina ONan, Jessica Wheatley, Jacob Daly

\section{PROFESSIONAL EXPERIENCE}

2005 Research assistant: Forest Department and Zoological Association of University of Peradeniya collaborative research group Faunal survey on Herpetofauna and Ichthyofauna at Kanneliya Forest Reserve, Sri Lanka

2005 Internship: Primate Division of National Zoological Garden, Sri Lanka Training included primate husbandry, nutrition and conservation

2004 Internship: National Aquatic Resource Agency, Sri Lanka 
Training included fish nutrition and feed preparation, husbandry and fish culture

2004 Research assistant: Department of Wildlife Conservation Survey of the elephant population in the Northwestern wildlife region, Sri Lanka

2004 Survey officer: International Water Management Institute Impact assessment of "Malaria control through irrigation water management"

\section{PUBLICATIONS}

Suriyampola, P.S., \& Eason, P.K. Sex Differences in Territorial Behavior of Neolamprologus multifaciatus. (In review - Acta Ethologica)

Suriyampola, P.S., \& Eason, P.K. Manipulating territories via landmarks. (In preparation- available on request)

Suriyampola, P.S., \& Eason, P.K. Effects of landmarks on territorial behavior of Hypsophrys nicaraguensis (In preparation - available on request)

\section{POPULAR PRESS}

Suriyampola, P.S. Meet me at the flagpole: Effects of Landmarks on Landscape of Aggression. Buntbarsche Bulletin. American Cichlid Association. (In preparation - available on request)

\section{PRESENTATIONS}

Suriyampola, P.S., \& Eason, P.K. 2013. Effects of Landmarks on Spatial Interactions in Territorial Neighbors. $50^{\text {th }}$ Annual meeting of Animal Behavior Society. University of Colorado, USA

Suriyampola, P.S., \& Eason, P.K. 2013. Meet me at the Flagpole: Effects of Landmarks on Territorial Behavior. Animal Behavior Conference. Indiana University. USA

Suriyampola, P.S., \& Eason, P.K. 2013. Effects of Landmarks on Territorial behavior of Hypsophrys nicaraguensis. Midwest Ecology and Evolution Conference, University of Notre Dame. USA 
Suriyampola, P.S., \& Eason P.K. 2012. Male and female Neolamprologus multifasciatus fight by different rules. $98^{\text {th }}$ Annual Meeting of Kentucky Academy of Science, Eastern Kentucky University. USA

Daly, J.A., Suriyampola, P.S., \& Eason, P.K. 2012. Effects of Size Asymmetry on Territorial Behavior in Skunk Loach Yasuhikotakia morleti. $98^{\text {th }}$ Annual Meeting of Kentucky Academy of Science, Eastern Kentucky University. USA

Daly, J.A., Suriyampola, P.S., \& Eason, P.K. 2012. Effects of Size Asymmetry on Territorial Behavior in Skunk Loach Yasuhikotakia morleti. SROP Undergraduate Poster Competition, University of Louisville. USA

Suriyampola, P.S., \& Eason, P.K. 2012. Effects of landmarks on territory size and shape. Biology Department Awards Day Seminar Series. University of Louisville. USA

Suriyampola, P.S., \& Eason, P.K. 2011. Gender differences in territorial defense in Neolamprologus multifasciatus. $48^{\text {th }}$ Annual meeting of Animal Behavior Society. Indiana University. USA

Suriyampola, P.S., \& Eason, P.K. 2009. Territoriality of Neolamprologus multifasciatus in clumped and dispersed resource habitats. $94^{\text {th }}$ Annual Meeting of Kentucky Academy of Science, Northern Kentucky University. USA

Wickramasinghe, N.S., Schier, L., Harbour, J.S., Magnusen, J.E., Wickramasinghe, A.K., Krishnasamy, A., Dougherty, S.M., Suriyampola, P.S., Schultz, D.J., \& Klinge, C.M. 2009. Anacardic acid induces apoptosis and inhibits DNA synthesis and invasion in breast cancer cell lines independent of estrogen receptor status. Plant based therapeutics symposium, Sullivan University, Louisville. USA

Suriyampola, P.S., De Silva, P.K. 2006. Field Ecology of Western Ceylon Palm Squirrel "Funambulus plamarum favonicus" in Kandy District. Annual Research Session, University of Peradeniya, Sri Lanka

\section{GRANTS}

2013

Doctoral Dissertation Completion Award, School of Interdisciplinary and Graduate Studies, University of Louisville Louisville 
2013 Biology Graduate Student Travel Grant, Department of Biology, University of Louisville

2013 Graduate Student Union Grant, College of Arts and Sciences, University of Louisville

2011

2011

2011

2010

2010

2010

AWARDS

2013

2012

2009

2006
Guy Jordan Research Award, American Cichlid Association

Graduate Student Travel Grant, Graduate Student Council, University of Louisville

Graduate Student Travel Grant, International Center, University of Louisville

Biology Graduate Student Research Grant, Department of Biology, University of Louisville

Idea Wild Equipment Grant

Graduate Student Creative Activity and Research Grant, College of Arts and Sciences, University of Louisville
Dean's Citation Award, University of Louisville

First place, Zoology session, Graduate Research Competition, $98^{\text {th }}$ Annual Meeting of Kentucky Academy of Sciences, Eastern Kentucky University

Second place, Zoology session, Graduate Research Competition, $94^{\text {th }}$ Annual Meeting of Kentucky Academy of Sciences, Northern Kentucky University

University Award for Academic Excellence, University of Peradeniya, Sri Lanka

\section{SCIENTIFIC OUTREACH/ COMMUNITY SERVICES}

Co-mentor for High School Science fair project:

Sarah Cheng, DuPont Manuel High School 
2008-2010 Secretary: Sri Lankan Student Association at University of Louisville. Louisville, USA

2005 Prepared a booklet series on the diversity and natural history of Herpetofauna \& Icthyofauna of Kanneliya Forest Reserve in collaboration with Forest Department, Sri Lanka.

\section{REFERENCES}

Dr. Perri Eason

Department of Biology

University of Louisville

Louisville, KY 40292

(502) 852-7730

perri.eason@louisville.edu

Dr. Paul Ewald

Department of Biology

University of Louisville

Louisville, KY 40292

(502) 852-8816

p0ewal01@ louisville.edu

Dr. James Alexander

Department of Biology

University of Louisville

Louisville, KY 40292

(502) 852-7243

jealex01@louisville.edu 